\title{
Bismuth Single Atoms Resulting from Transformation of Metal-Organic Frameworks and Their Use as Electrocatalysts for $\mathrm{CO}_{2}$ Reduction
}

Erhuan Zhang, ${ }^{1 \dagger}{ }^{1+}$ Tao Wang, ${ }^{3+} \mathrm{Ke} \mathrm{Yu},{ }^{2 \dagger}$ Jia Liu, ${ }^{1}$ Wenxing Chen, ${ }^{1}$ Ang Li,${ }^{4}$ Hongpan Rong,${ }^{1 *}$ Rui Lin, ${ }^{2}$ Shufang Ji, ${ }^{2}$ Xusheng Zheng, ${ }^{5}$ Yu Wang, ${ }^{6}$ Lirong Zheng, ${ }^{7}$ Chen Chen, ${ }^{2}$ Dingsheng Wang,$^{2^{*}}$ Jiatao Zhang, ${ }^{1^{*}}$ and Yadong $\mathrm{Li}^{2^{*}}$

${ }^{1}$ Beijing Key Laboratory of Construction-Tailorable Advanced Functional Materials and Green Applications, Experimental Center of Advanced Materials, School of Materials Science \& Engineering, Beijing Institute of Technology, Beijing 100081, China

2 Department of Chemistry, Tsinghua University, Beijing 100084, China

${ }^{3}$ SUNCAT Center for Interface Science and Catalysis, Department of Chemical Engineering, Stanford University, Stanford, California 94305, USA.

${ }^{4}$ Beijing Key Laboratory of Microstructure and Property of Advanced Materials, Beijing University of Technology, Beijing, China

${ }^{5}$ National Synchrotron Radiation Laboratory, University of Science and Technology of China, Hefei 230029, China

${ }^{6}$ Shanghai Synchrotron Radiation Facilities, Shanghai Institute of Applied Physics, Chinese Academy of Science, Shanghai 201204, China

${ }^{7}$ Beijing Synchrotron Radiation Facility, Institute of High Energy Physics, Chinese Academy of Sciences, Beijing, China

${ }^{\dagger} \mathrm{E}$. Zhang, T. Wang, and K. Yu contributed equally to this work. 
Table of Contents

1. Material Synthesis and Characterization

2. Electrochemical Measurements

3. Supporting Figures, Tables, and Movie

4. References 


\section{Material Synthesis and Characterization}

Chemicals and Materials. Bismuth nitrate pentahydrate $\left(\mathrm{Bi}\left(\mathrm{NO}_{3}\right)_{3} \cdot 5 \mathrm{H}_{2} \mathrm{O}\right)$, methanol anhydrous $\left(\mathrm{CH}_{3} \mathrm{OH}\right.$ or $\left.\mathrm{MeOH}\right), 1,3,5$-benzenetricarboxylic acid $\left(\mathrm{H}_{3} \mathrm{BTC}\right)$ were purchased from Sinopharm Chemical Reagent Co. Ltd. and used without further purification too. Ethanol, and isopropyl alcohol were purchased from Shanghai Chemical Reagent Co. Ltd. Nafion (5 wt\%) were from Sigma-Aldrich. Sodium carbonate (99.999\%) was purchased from Acros. $18.2 \mathrm{M} \Omega$ $\mathrm{cm}$ ultrapure water was obtained from milli-Q integral system. High purity carbon dioxide gas (99.999\%) and helium gas (99.9999\%) were purchased from Praxair. The carbon paper sigracet39BC was purchased from FuelCellsEtc; Nafion 117 membrane was purchased from Dupont. Doubly distilled deionized water (DIW, $18.2 \mathrm{M} \Omega \mathrm{cm}$ ) was used for all $\mathrm{CO}_{2}$ electroreduction tests.

\section{Experimental Section}

\section{Synthesis of Bi-MOF}

The Bi-MOF was prepared by solvothermal method reported in the literature. The synthesis was carried out under solvothermal conditions in $100 \mathrm{ml}$ Teflon lined steel reactor. In a typical synthesis, $\mathrm{H}_{3} \mathrm{BTC}(750 \mathrm{mg})$ and $\mathrm{Bi}\left(\mathrm{NO}_{3}\right)_{3} \cdot 5 \mathrm{H}_{2} \mathrm{O}(150 \mathrm{mg})$ were added in a mixture of $\mathrm{DMF} / \mathrm{MeOH}(60 \mathrm{~mL}, 4: 1)$ at room temperature. The transparent mixture was transfered into the reactor after the powder was dissolved. Then sealed the reactor and heated it to $120^{\circ} \mathrm{C}$ for $24 \mathrm{~h}$. The obtained white powder was collected by centrifugation, and washed with $\mathrm{MeOH}$. After drying in an oven $\left(80^{\circ} \mathrm{C}, 6 \mathrm{~h}\right)$, the product was identified by XRD as pure Bi-MOF.

\section{Synthesis of Bi SAs/NC.}

The as-prepared Bi-MOF precursor and $300 \mathrm{mg}$ dicyandiamide in two porcelain boats were placed at two separate positions in the tube furnace and heated to $1000{ }^{\circ} \mathrm{C}$ (heating rate $2{ }^{\circ} \mathrm{C}$ $/ \mathrm{min})$ for $3 \mathrm{~h}$ in a stream of $\operatorname{Ar}(8 \mathrm{~mL} / \mathrm{min})$ to yield Bi SAs$/ \mathrm{NC}$. The Bi content was measured to be $0.2 \mathrm{wt} \%$ based on ICP-AES analysis.

\section{Synthesis of Bi Cs/NC.}

The as-prepared Bi-MOF precursor was placed in a porcelain boat and heated to $1000{ }^{\circ} \mathrm{C}$ (heating rate $\left.2{ }^{\circ} \mathrm{C} / \mathrm{min}\right)$ for $3 \mathrm{~h}$ in a stream of $\operatorname{Ar}(8 \mathrm{~mL} / \mathrm{min})$ to yield $\mathrm{Bi} \mathrm{Cs} / \mathrm{NC}$.

\section{Synthesis of Bi NPs/NC}

The as-prepared Bi-MOF precursor and $300 \mathrm{mg}$ dicyandiamide in a porcelain boat were placed at two separate positions of the tube furnace and heated to $800{ }^{\circ} \mathrm{C}$ (heating rate $2{ }^{\circ} \mathrm{C}$ $/ \mathrm{min}$ ) for $3 \mathrm{~h}$ in a stream of $\operatorname{Ar}(8 \mathrm{~mL} / \mathrm{min})$ to yield $\mathrm{Bi} \mathrm{NPs} / \mathrm{NC}$.

\section{Characterizations}


Low-resolution transmission electron microscopy (TEM) images were obtained by HITACHI $\mathrm{H}-7650$ (accelerating voltage of $80 \mathrm{kV}$ ) electron microscopy. The high-resolution TEM, HAADF-STEM images the corresponding Electron energy-loss spectroscopy were recorded by a FEI Tecnai G2F20 S-Twin high-resolution transmission electron microscope working at $200 \mathrm{kV}$ and on a JEOL JEM-ARM200F TEM/STEM with a spherical aberration corrector working at $300 \mathrm{kV}$. The powder X-ray diffraction measurements were performed using a Bruker D8 multiply crystals X-ray diffratometer (5 ${ }^{\circ}$ per min). The X-ray photoelectron spectroscopy (XPS) analyse was performed on a PerkinEImer Physics PHI 5300 spectrometer. The SEM was carried out by a JSM-6700F SEM. Nitrogen and $\mathrm{CO}_{2}$ sorption measurement were conducted using a Micromeritics ASAP 2020 system. Fourier transform infrared spectra (FT-IR) of the samples were recorded on a VECTOR-22FT-IR spectrometer over potassium bromide pellet. Raman scattering spectra were recorded with a Renishaw System 2000 spectrometer using the $514.5 \mathrm{~nm}$ line of $\mathrm{Ar}^{+}$for excitation. In situ environmental microscopic study. The in situ environmental microscopic study is performed on a Titan ETEM microscope (FEI) operated at $300 \mathrm{kV}$ equipped with an image Cs-corrector. ${ }^{1} \mathrm{H}$ nuclear magnetic resonance (NMR) was recorded with a Bruker Advance III $(400 \mathrm{MHz})$ spectrometer. The XANES spectra (C K-edge and N K-edge) were measured at beamline BL12B of National Synchrotron Radiation Laboratory (NSRL) of China. The samples were deposited onto double-sided carbon tape for $\mathrm{X}$ ray spectroscopy. XAFS measurement and data analysis: XAFS spectra at the Bi L-edge was collected at BL14W1 station in Shanghai Synchrotron Radiation Facility (SSRF). The Bi L-edge XANES data were recorded in a fluorescence mode. We pelletized all samples as disks of $10 \mathrm{~mm}$ diameter with $1 \mathrm{~mm}$ thickness by using polyvinylidene fluoride (PVDF) powder as binder. $\mathrm{Bi}$ foil and $\mathrm{Bi}_{2} \mathrm{O}_{3}$ were used as references. All spectra were collected in ambient conditions. The station was operated with a Si (111) double crystal monochromator.

\section{Electrochemical Measurements}

$0.1 \mathrm{M} \mathrm{NaHCO}_{3}$ aqueous solution $(\mathrm{pH}=7)$ was obtained by bubbling $\mathrm{CO}_{2}$ to the sodium carbonate aqueous solution overnight. The $\mathrm{H}$-type cell was used as the electrolyzer for $\mathrm{CO}_{2}$ electrochemical reduction. Nafion 117 membrane was inserted between the cathodic chamber and anodic chamber. A mass flow controller was used to set the $\mathrm{CO}_{2}$ flow rate at $20 \mathrm{sccm}$. The sigracet39BC carbon paper, $\mathrm{Pt}$ wire and $\mathrm{Ag} / \mathrm{AgCl}$ was used as working electrode, counter electrode and reference electrode respectively. The LSV curves were conducted with the Princeton PMC-500 electrochemical workstation with scan rate of $10 \mathrm{mV} / \mathrm{s}$. All the potential were reported with respect to the reversible hydrogen electrode (RHE) and corrected by iR drop compensation. The potential $(E)$ values in the electrochemical measurements were

corrected by the equation $E=E_{\text {applied }}-i R$, where $E_{\text {applied }}$ is the potential applied, and $i$ is the current flowing through the cell. The chronoamperometry tests were conducted at each potential for $40 \mathrm{~min}$. The gas products of electrolysis were detected on the Shimazu 2010 plus 
gas chromatography equipped with BID detector and ShinCarbon ST 100/120 packed column. High purity helium (99.9999\%) was used as the carrier gas for the chromatography. The liquid products of electrolysis were analyzed by Bruker Avance III HD 400 NMR. The Faraday efficiency of gas products was calculated by the equation: $\frac{2 \times 96485(\mathrm{c} / \mathrm{mol}) \times V(\mathrm{~mL} / \mathrm{min}) \times 10^{-6}\left(\mathrm{~m}^{3} / \mathrm{mL}\right) \times v(\mathrm{vol} \%) \times 1.013 \times 10^{5}\left(\mathrm{~N} / \mathrm{m}^{2}\right)}{8.314(\mathrm{~N} \cdot \mathrm{m} / \mathrm{mol} \cdot \mathrm{K}) \times 298.15 \mathrm{~K} \times \mathrm{I}_{\text {total }}(\mathrm{C} / \mathrm{s}) \times 60(\mathrm{~s} / \mathrm{min})}$

$\mathrm{v}(\mathrm{vol} \%)=$ volume concentration of $\mathrm{CO}$ in the exhaust gas from the cell (GC data). $\mathrm{V}(\mathrm{mL} / \mathrm{min})$ $=$ Gas flow rate measured by a flow meter at the exit of the cell at room temperature and under ambient pressure. $\mathrm{I}_{\text {total }}(\mathrm{C} / \mathrm{s})=$ steady-state cell current.

$$
\mathrm{T} 0 \mathrm{~F}=\frac{\mathrm{I}_{\text {product }} / n F}{m_{\text {cat }} \omega / \mathrm{M}_{\mathrm{Bi}}}
$$

TOF: turnover frequency, $\mathrm{h}^{-1}$.

$I_{\text {product: }}$ partial current for certain product, $A$.

$\mathrm{n}$ : the number of electron transferred for product formation, which is 2 for both $\mathrm{CO}$ and $\mathrm{H}_{2}$ production.

F: Faradaic constant, $96485 \mathrm{C} \mathrm{mol}^{-1}$.

$\mathrm{m}_{\text {cat }}$ : catalyst mass in the electrode, $\mathrm{g}$.

$\omega$ : Bi loading in the catalyst.

$\mathrm{M}_{\mathrm{Bi}}$ : atomic mass of $\mathrm{Bi}, 208.98 \mathrm{~g} \cdot \mathrm{mol}^{-1}$.

Both $\mathrm{CO}_{2}$ reduction and HER make contribution for the current in aqueous electrolyte. No liquid products are detected after electrolysis. $\mathrm{CO}$ is the main product of $\mathrm{CO}_{2}$ electrolysis for $\mathrm{Bi}$ $\mathrm{SAs} / \mathrm{NC}$ whereas $\mathrm{H}_{2}$ is the main product for both $\mathrm{Bi} \mathrm{Cs} / \mathrm{NC}$ and Bi NPs/NC.

\section{Computational details}

All the DFT calculations were carried out with the Vienna Ab Initio Simulation Package (VASP). ${ }^{1,2}$ The electron ion interaction was described with the projector augmented wave (PAW) method. ${ }^{3,4}$ The electron exchange and correlation energy was treated within the generalized gradient approximation in the Perdew-Burke-Ernzerhof formalism (GGA-PBE). ${ }^{5}$ An energy cut-off of $400 \mathrm{eV}$ and a second-order Methfessel-Paxton electron smearing with $\sigma=$ $0.2 \mathrm{eV}$ were used to acquire accurate energies with errors less than $1 \mathrm{meV}$ per atom. Spin polarization was included throughout our computations. The dispersion correction was described with DFT-D3 method of Grimme. ${ }^{6}$ The structure optimization was done when the force tolerance and energy difference became lower than $0.02 \mathrm{eV} / \AA$ and $10^{-5} \mathrm{eV}$, respectively.

The Bi SAs/NC catalyst was modeled by a $p(4 \times 4)$ supercell of graphene doped with nitrogen and $\mathrm{Bi}\left(\mathrm{BiN}_{4} / \mathrm{C}\right)$ was shown in Figure S27a. As comparisons, pure $\mathrm{Bi}$ and $\mathrm{Bi} / \mathrm{C}$ catalysts were simulated with a $p(2 \times 4)-\mathrm{Bi}(110)$ surface in Figure $\mathrm{S} 27 \mathrm{~b}$ and $\mathrm{Bi}$ doped $p(4 \times 4)$ supercell of graphene in Figure 27c, respectively. $\mathrm{Bi}(110)$ surface was regarded as Bi NPs/NC. A vacuum layer of $15 \AA$ was set between the periodically repeated slabs to avoid strong 
interactions. The most stable adsorption configurations of $\mathrm{CO}_{2}, \mathrm{COOH}, \mathrm{HCOO}, \mathrm{CO}$ and $\mathrm{H}$ on each catalyst were located by considering all the possible adsorption sites on each surface, and the schematic structures of them were given in Figures S28-S30.

The $\mathrm{CO}_{2}$ reduction to $\mathrm{CO}$ mechanism contains proton-electron transfers: (1) $\mathrm{CO}_{2}(\mathrm{~g})+{ }^{*}+$ $\mathrm{e}^{-} \leftrightarrow{ }^{*} \mathrm{CO}_{2}{ }^{-},(2){ }^{*} \mathrm{CO}_{2}{ }^{-}+\mathrm{H}^{+}(\mathrm{aq}) \leftrightarrow{ }^{*} \mathrm{COOH} ;(3){ }^{*} \mathrm{COOH}+\mathrm{e}^{-}+\mathrm{H}^{+}(\mathrm{aq}) \leftrightarrow{ }^{*} \mathrm{CO}+\mathrm{H}_{2} \mathrm{O}$; (4) ${ }^{*} \mathrm{CO}$ $\leftrightarrow \mathrm{CO}(\mathrm{g})+{ }^{*}$, where asterisk * denotes the active site on catalyst surface. For comparison, the format reaction pathway was also considered, i.e., (1) ${ }^{*} \mathrm{CO}_{2}{ }^{-}+\mathrm{H}^{+}(\mathrm{aq}) \leftrightarrow \mathrm{HCOO}^{*}$, (2) $\mathrm{HCOO}^{*}$ $+\mathrm{e}^{-}+\mathrm{H}^{+}(\mathrm{aq}) \leftrightarrow \mathrm{HCOOH}(\mathrm{g})$. The reaction mechanism was simulated with computational hydrogen electrode $(\mathrm{CHE})$ model developed by Norskov group, ${ }^{7,8}$ which provides an elegant approach of avoiding the explicit treatment of solvated protons. At zero voltage, $\mathrm{pH}=0, p=1$ bar, $T=298.15 \mathrm{~K}$, the Gibbs free energy change $\left(\Delta G_{0}\right)$ of a reaction (i.e., $\mathrm{R}^{*}+\mathrm{H}^{+}+\mathrm{e}^{-} \leftrightarrow R \mathrm{H}^{*}$ ) was described as the free energy of the reaction $R^{*}+1 / 2 \mathrm{H}_{2} \leftrightarrow R H^{*}$. Then, $\Delta \mathrm{G}_{0}=\Delta E+\Delta Z P E+$ $\Delta \mathrm{H}-\mathrm{T} \Delta \mathrm{S}$, where $\Delta E=E$ (product) $-E$ (reactant); $\Delta \mathrm{ZPE}, \Delta \mathrm{H}$ and $\Delta \mathrm{S}$ are the differences in zero-point energy, enthalpy and entropy, which were calculated within the harmonic approximation for surface species. The chemical potential of the proton-electron pair can be described as a function of the applied potential, i.e., $\Delta G_{U}=-e U$, where $U$ is the applied electrode potential relative to the standard hydrogen electrode. The $\mathrm{pH}$ effect was described by $\Delta G_{\mathrm{pH}}=-\mathrm{k} \operatorname{Tn}\left[\mathrm{H}^{+}\right]=\mathrm{k} \operatorname{Tln} 10 \times \mathrm{pH}$. Eventually, the Gibbs free energy changes of a reaction could be calculated with the following formula: $\Delta G=\Delta G_{0}+\Delta G_{p H}+\Delta G_{\mathrm{U}}$. We also considered the $\mathrm{H}_{2}$ evolution reaction since it is regarded as the major competitive reaction. Previous study proposed the difference between limiting potentials for $\mathrm{CO}_{2}$ reduction and $\mathrm{H}_{2}$ evolution (i.e., $\mathrm{U}_{\mathrm{L}}\left(\mathrm{CO}_{2}\right)-\mathrm{U}_{\mathrm{L}}\left(\mathrm{H}_{2}\right)$, where $\left.\mathrm{U}_{\mathrm{L}}=-\Delta \mathrm{G}_{0} / \mathrm{e}\right)$ is able to reflect the selectivity of $\mathrm{CO}_{2}$ reduction reactions, ${ }^{9}$ and a more positive $\mathrm{U}_{\mathrm{L}}\left(\mathrm{CO}_{2}\right)-\mathrm{U}_{\mathrm{L}}\left(\mathrm{H}_{2}\right)$ value indicates a higher selectivity. 


\section{Supporting Figures and Tables}

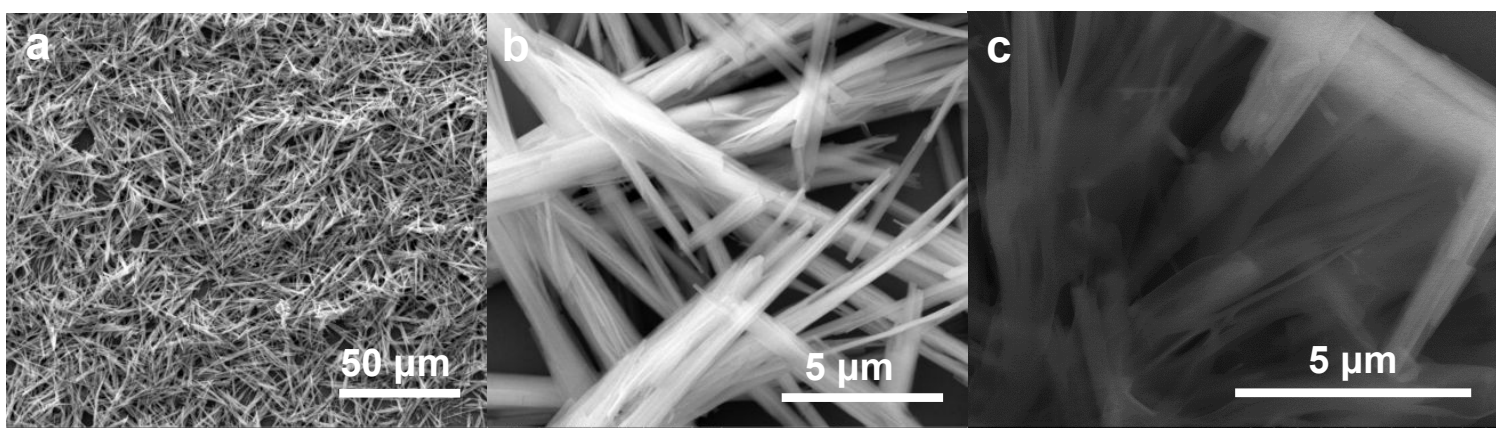

Figure S1. (a-c) SEM images of Bi-MOF with different magnifications.
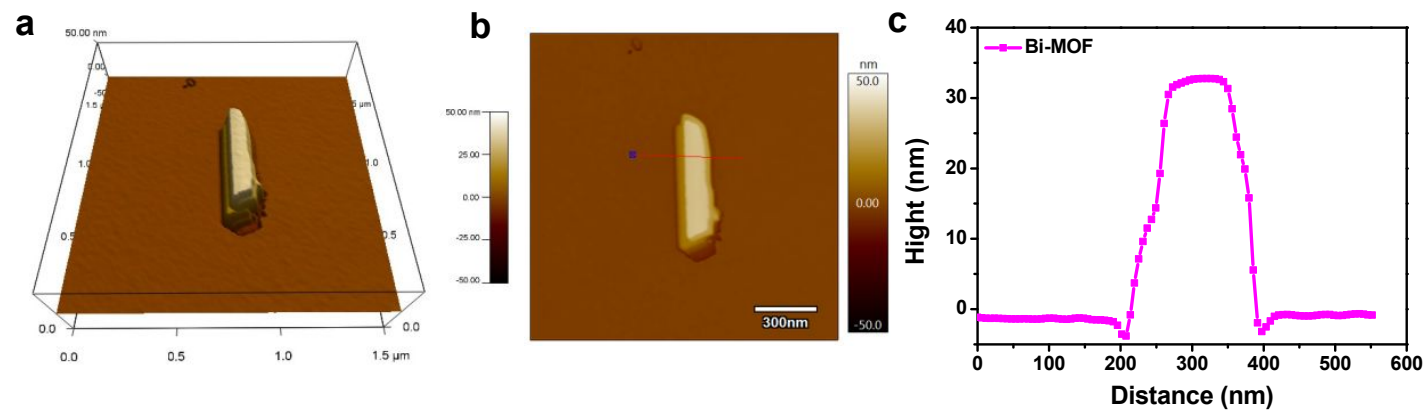

Figure S2. (a, b) AFM images, and (c) the corresponding height profile of Bi-MOF. As shown in the Figure S2c, the total height was of four layers of nanobelt. The average thickness of nanobelt was determined to be about $8 \mathrm{~nm}$ by atomic force microscopy (AFM). 

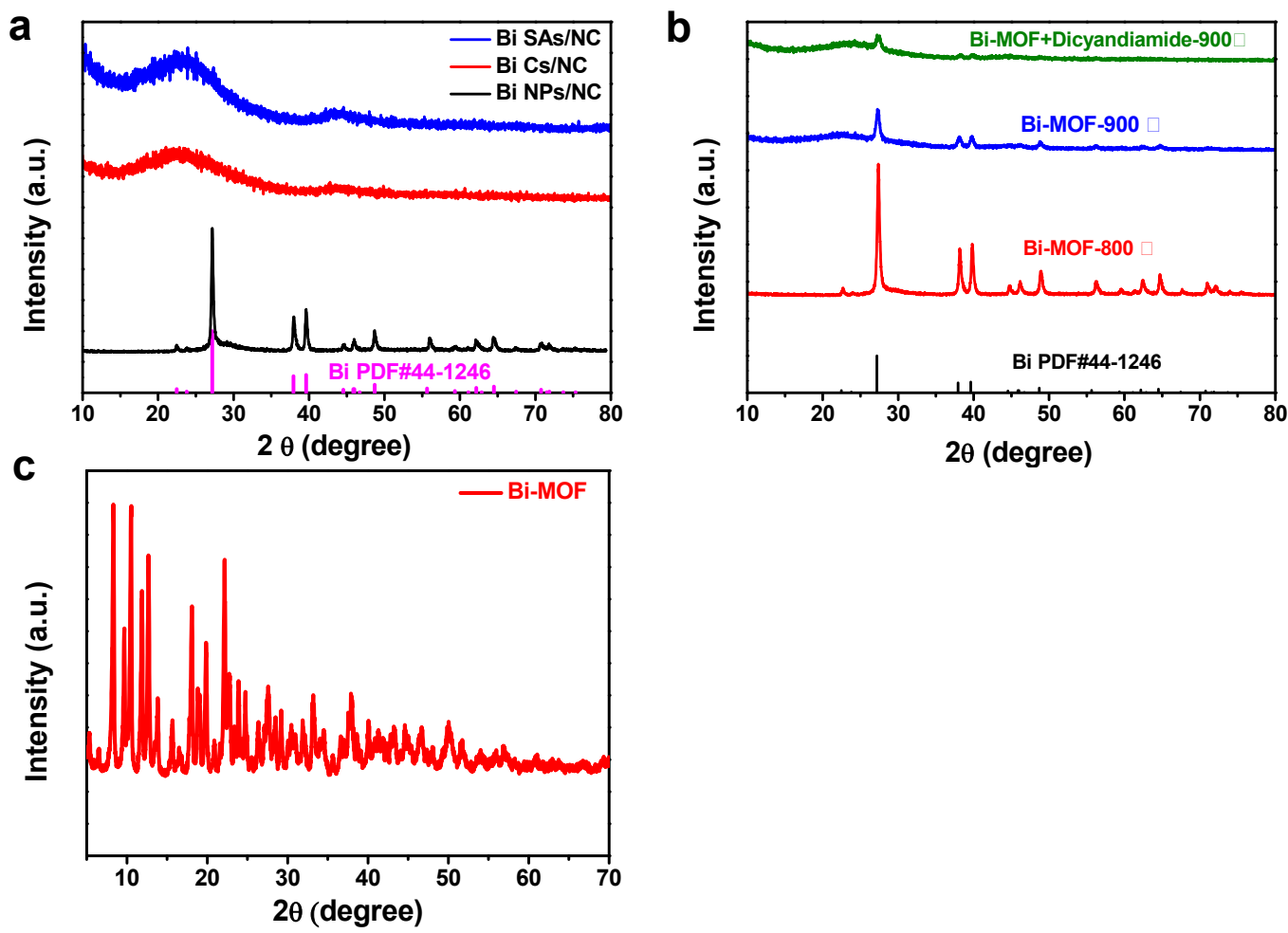

Figure S3. XRD patterns of the as-prepared different samples. 


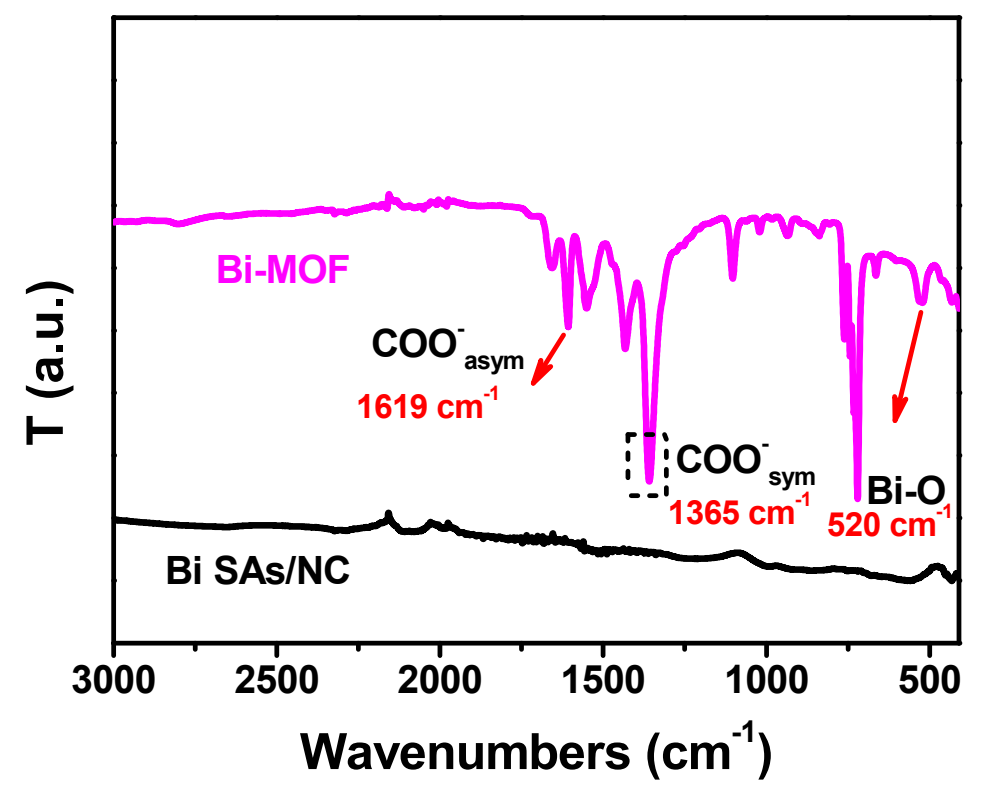

Figure S4. The IR spectra of the as-prepared $\mathrm{Bi}$ SAs/NC and Bi-MOF, respectively. For the Bi-MOF, two strong peaks at $1619 \mathrm{~cm}^{-1}$ and $1365 \mathrm{~cm}^{-1}$ are observed, which are assigned to the asymmetric and symmetric vibrations of carboxylate anions in BTC anions, respectively. The two peaks (at 1619 and $1365 \mathrm{~cm}^{-1}$ ) shift to shorter wavenumber compared to those of $\mathrm{H}_{3} \mathrm{BTC}$ (1720 and $\left.1403 \mathrm{~cm}^{-1}\right),{ }^{10}$ suggesting the coordination of the Ocoo- of BTC anions with bismuth. Besides that, the symmetrical stretching vibration of the $\mathrm{Bi}-\mathrm{O}$ bond was observed at $520 \mathrm{~cm}^{-1}$, which further supports the bonding of $\mathrm{Bi}$ cation and BTC anions. ${ }^{11}$

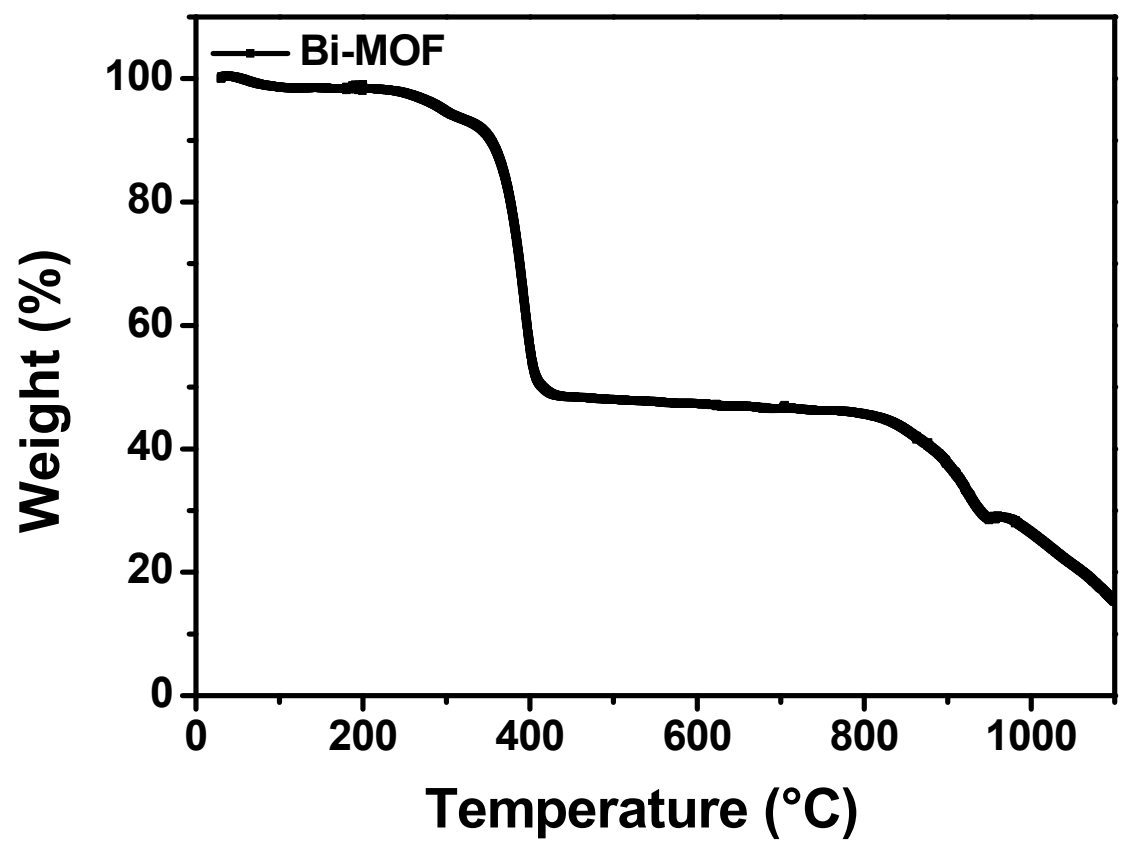

Figure S5. TGA pattern of Bi-MOF. 


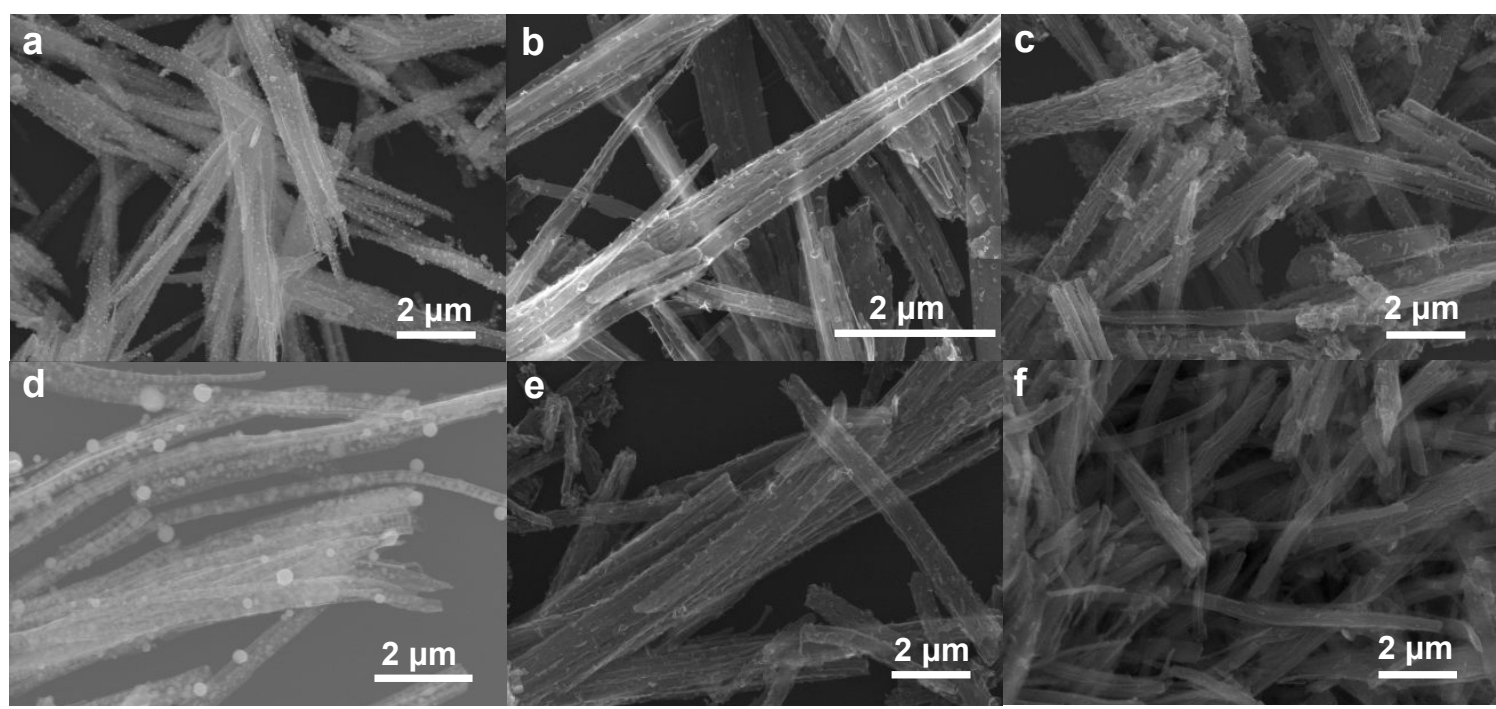

Figure S6. (a-c) SEM images of Bi-MOF pyrolyzed (a-c) with and (d-f) without dicyandiamide at (a, d) 800, (b, e) 900 and (c, f) $1000^{\circ} \mathrm{C}$, respectively.

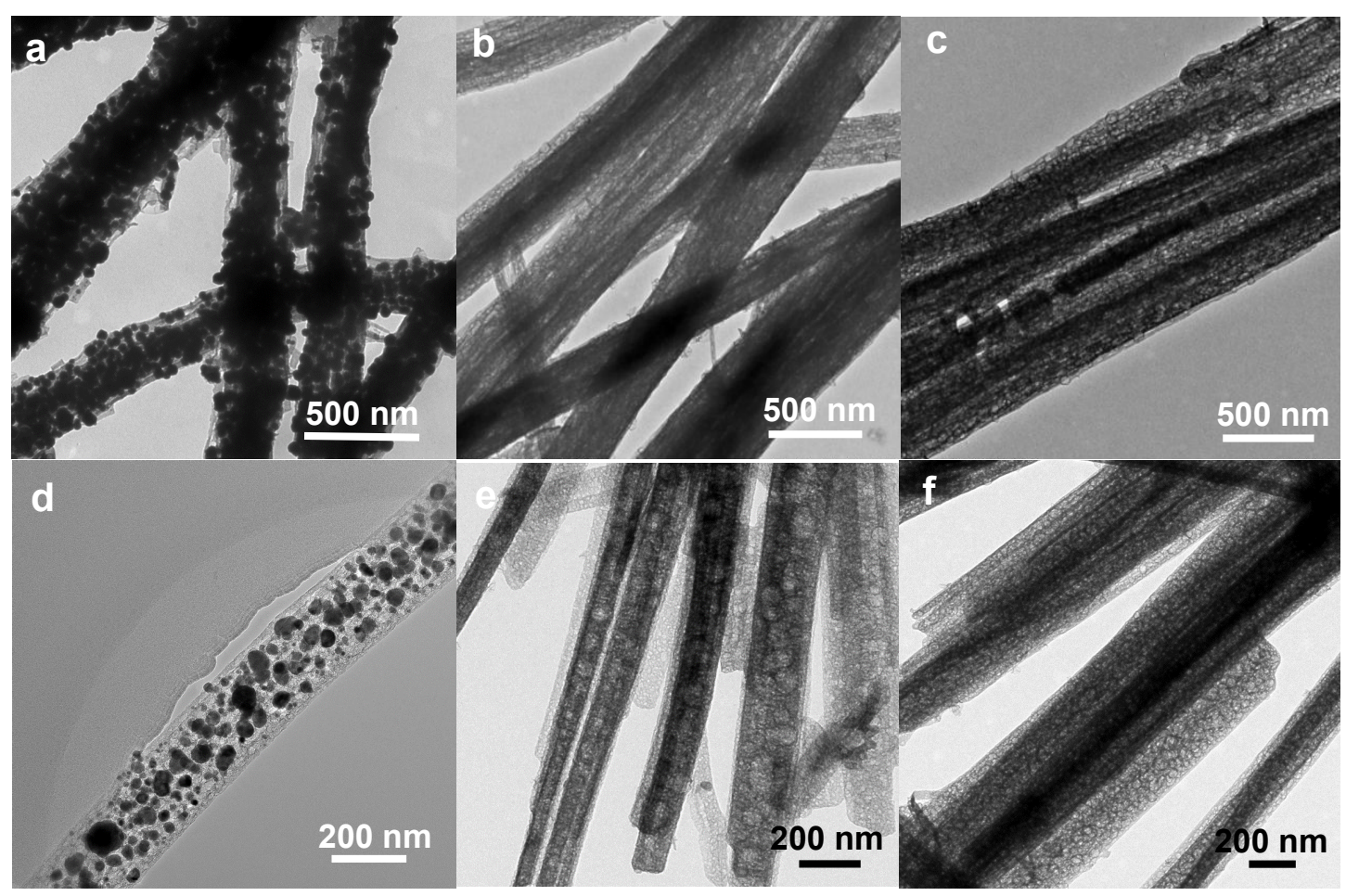

Figure S7. TEM images of Bi-MOF pyrolyzed (a-c) with and (d-f) without dicyandiamide at (a, d) 800 , (b, e) 900 and (c, f) $1000^{\circ} \mathrm{C}$, respectively. 


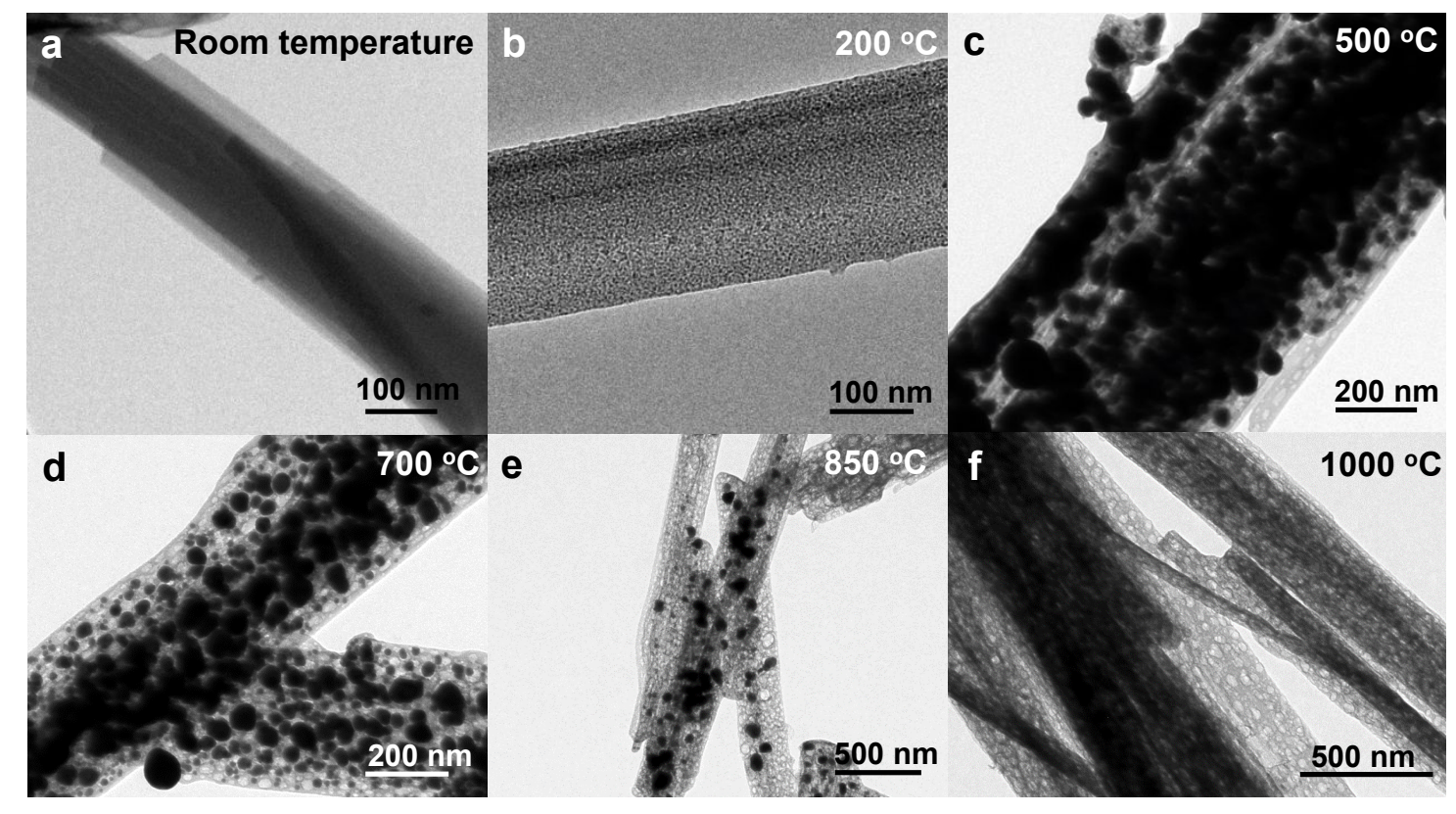

Figure S8. (a-f) TEM images of product of Bi-MOF and dicyandiamide at various temperatures in tube furnace. 

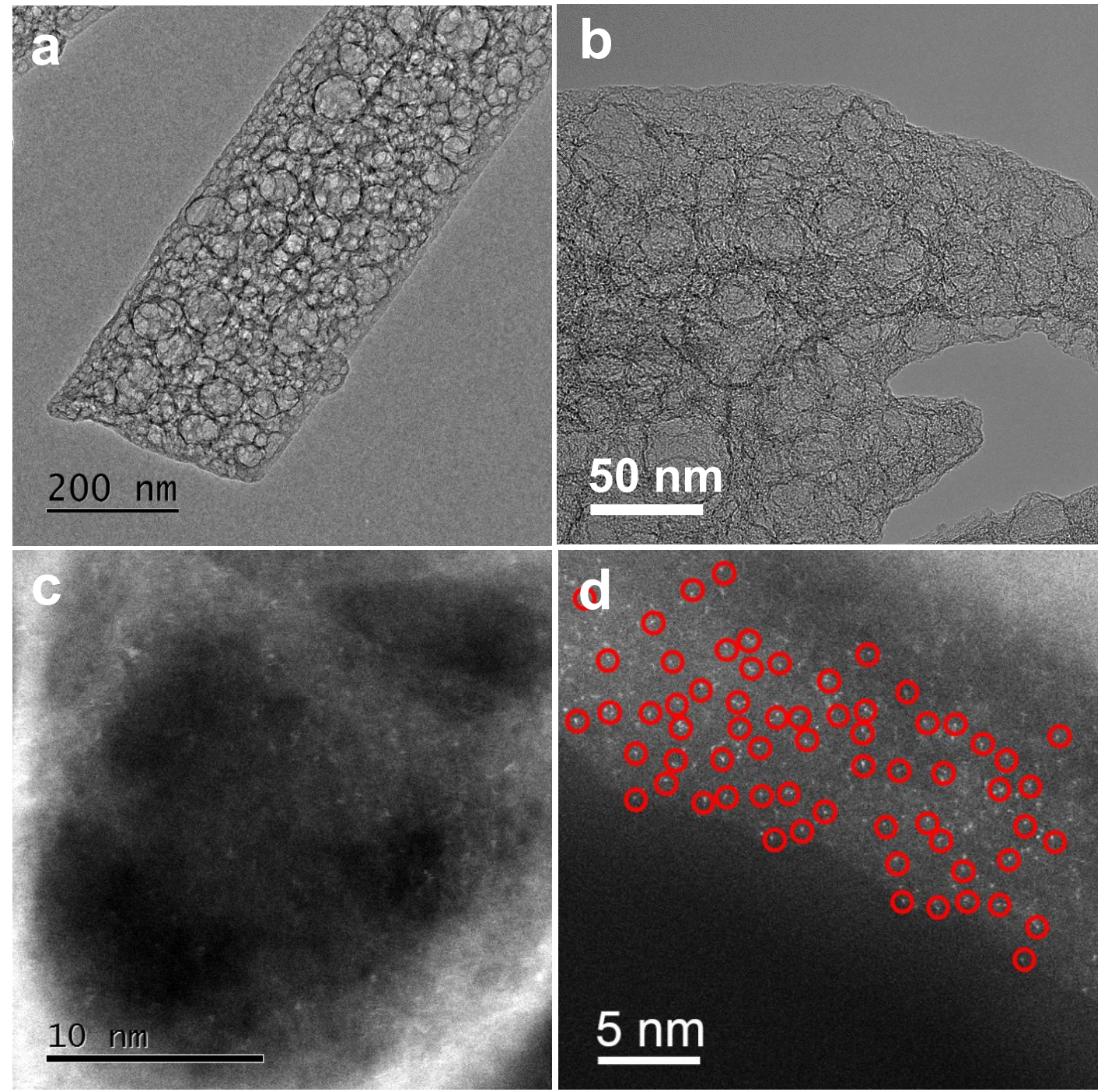

Figure 59. $(a, b)$ The HRTEM and (c, d) AC-STEM-HAADF images of Bi SAs/NC from different regions at different magnifications. 

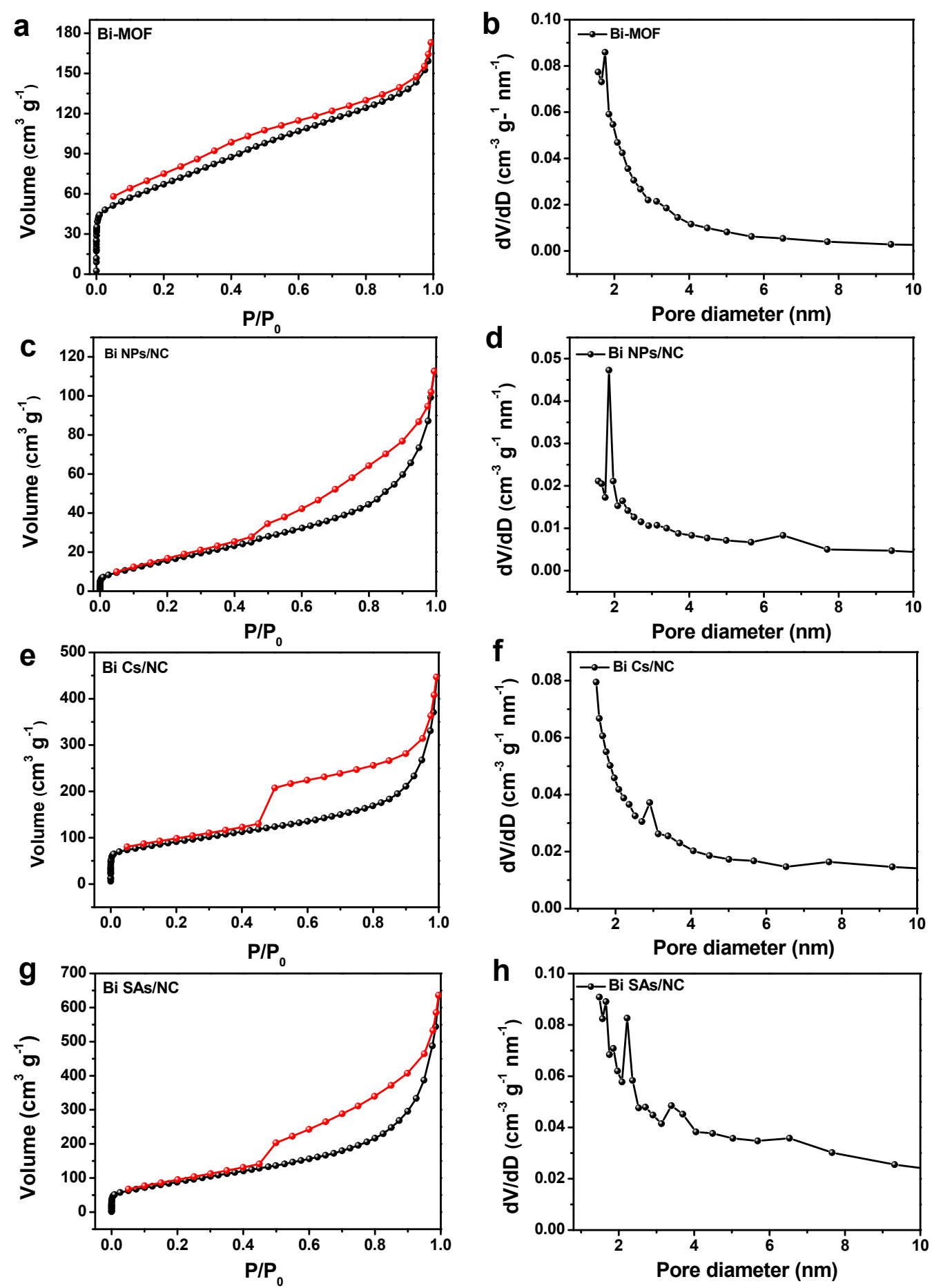

Figure S10. (a,c,e,g) Nitrogen adsorption-desorption isotherms and $(b, d, f, h)$ pore size distributions of Bi-MOF, Bi NPs/NC, Bi Cs/NC, and Bi SAs/NC, respectively. 


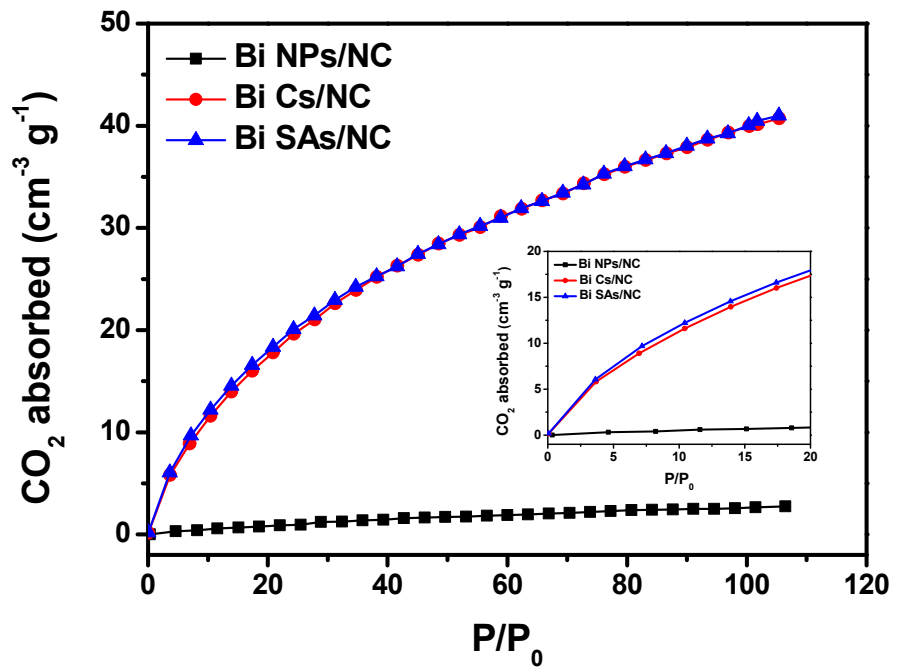

Figure S11. $\mathrm{CO}_{2}$ adsorption-desorption isotherms of the $\mathrm{Bi} \mathrm{NPs} / \mathrm{NC}, \mathrm{Bi} \mathrm{Cs} / \mathrm{NC}$, and $\mathrm{Bi} \mathrm{SAs}$ NC. 


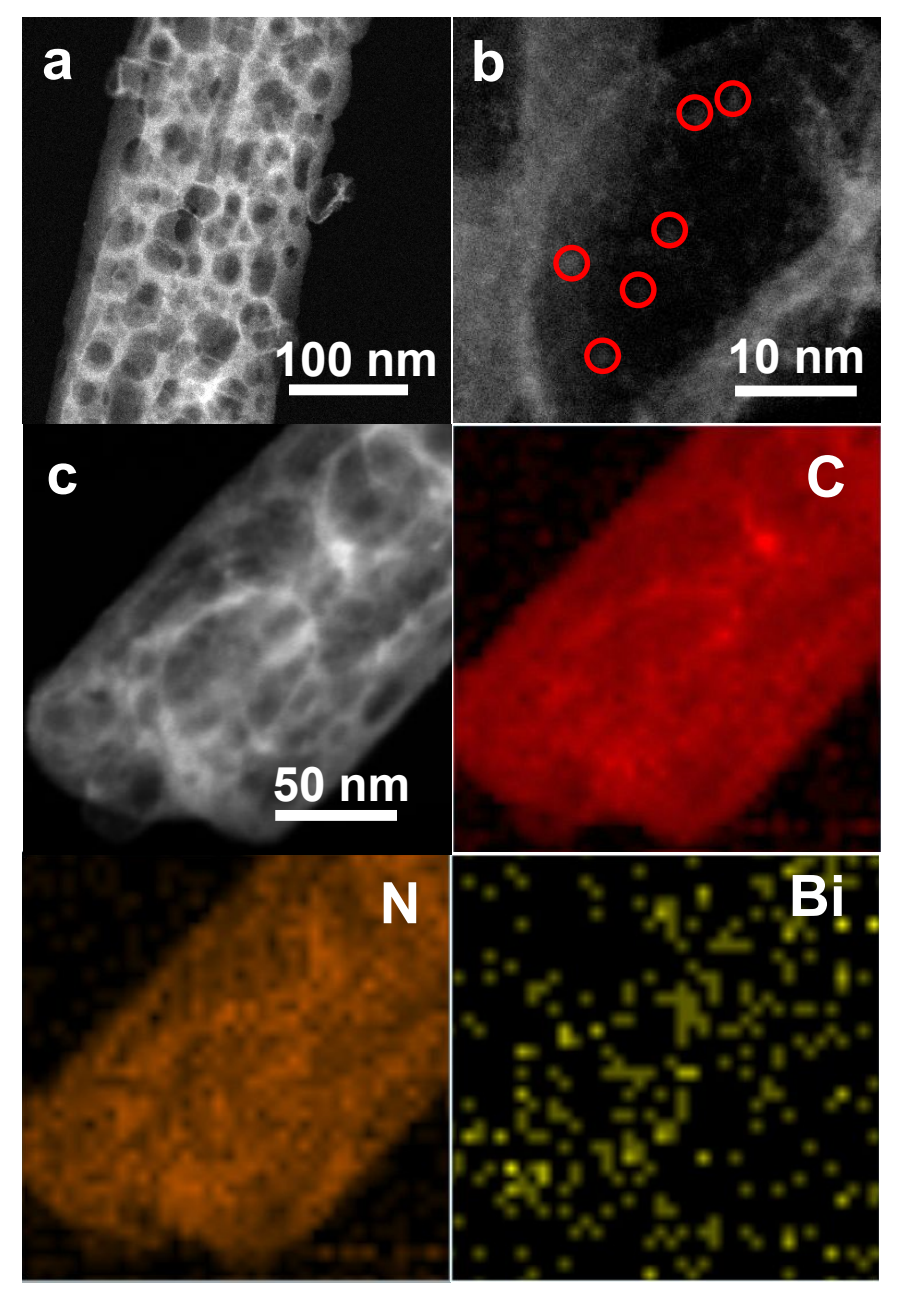

Figure S12. The STEM images of $\mathrm{Bi}$ clusters/NC (Bi Cs/NC) and corresponding EDS images. By comparison, when we heated the Bi-MOF without $D C D$ at $1000^{\circ} \mathrm{C}, \mathrm{Bi} \mathrm{Cs} / \mathrm{NC}$ was obtained. The porous characteristic of $\mathrm{Bi} C s / \mathrm{NC}$ was also revealed by STEM images ( $a$ and $b$ ). Further investigation by HAADF-STEM showed that the $\mathrm{Bi}$ clusters well dispersed in the host framework, suggesting the Ar flow was unable to haul the Bi atoms without the help of $D C D(b)$. Besides, the EDS mapping images collaboratively supported the $\mathrm{Bi} \mathrm{Cs}$ distributed homogenously in the whole composite (c). 


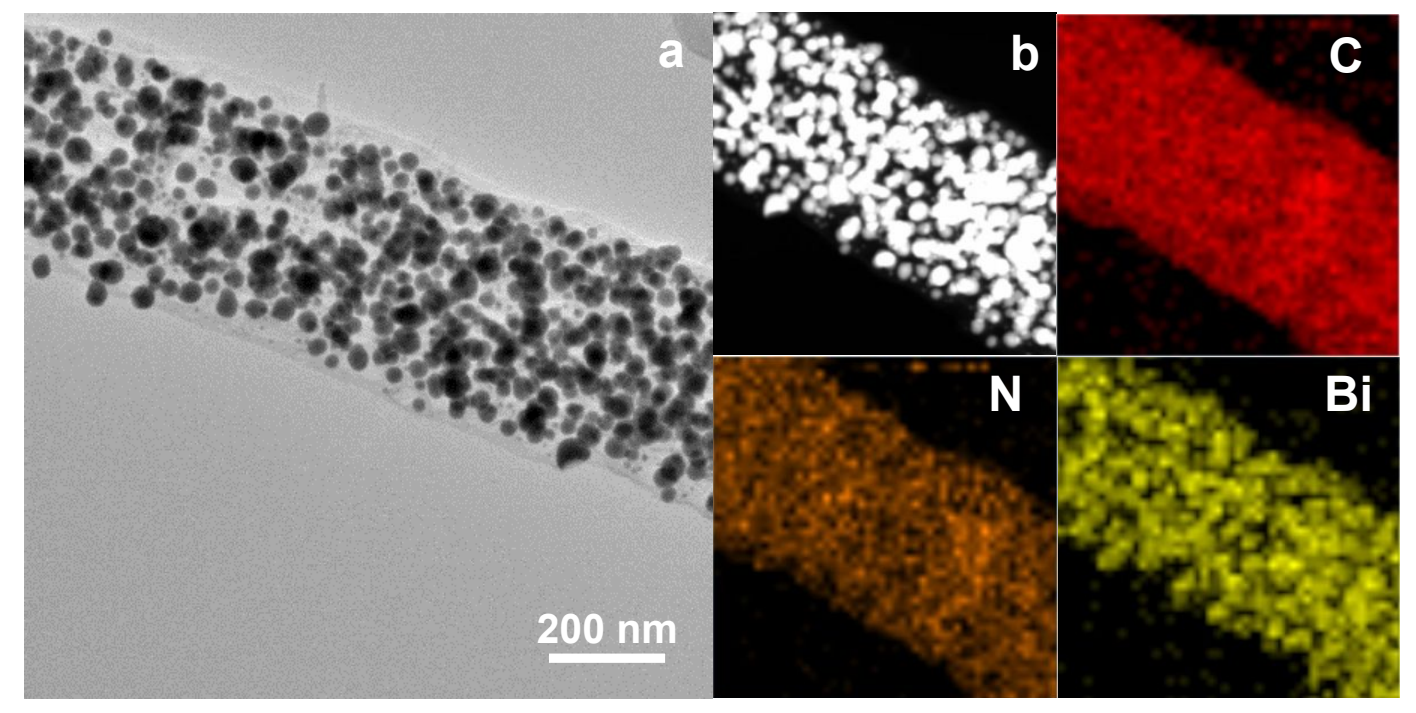

Figure S13. The (a) HRTEM, (b) HAADF-STEM images of Bi NPs/NC and corresponding EDS images.
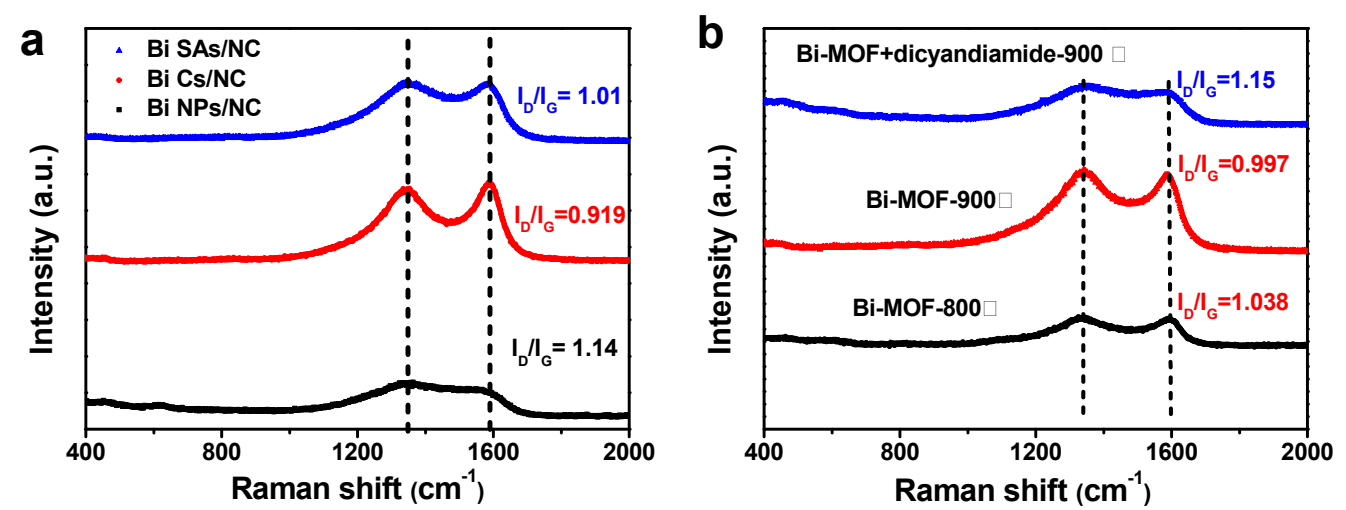

Figure S14. Raman spectra of different samples. The ratio $I_{D} / I_{G}(D$, disorder; $G$, graphene) for $\mathrm{Bi} \mathrm{SAs} / \mathrm{NC}$ was higher than that of $\mathrm{Bi} \mathrm{Cs} / \mathrm{NC}$, indicating that the ammonia gas generated from pyrolysis process of DCD created abundant defect sites in carbon. 

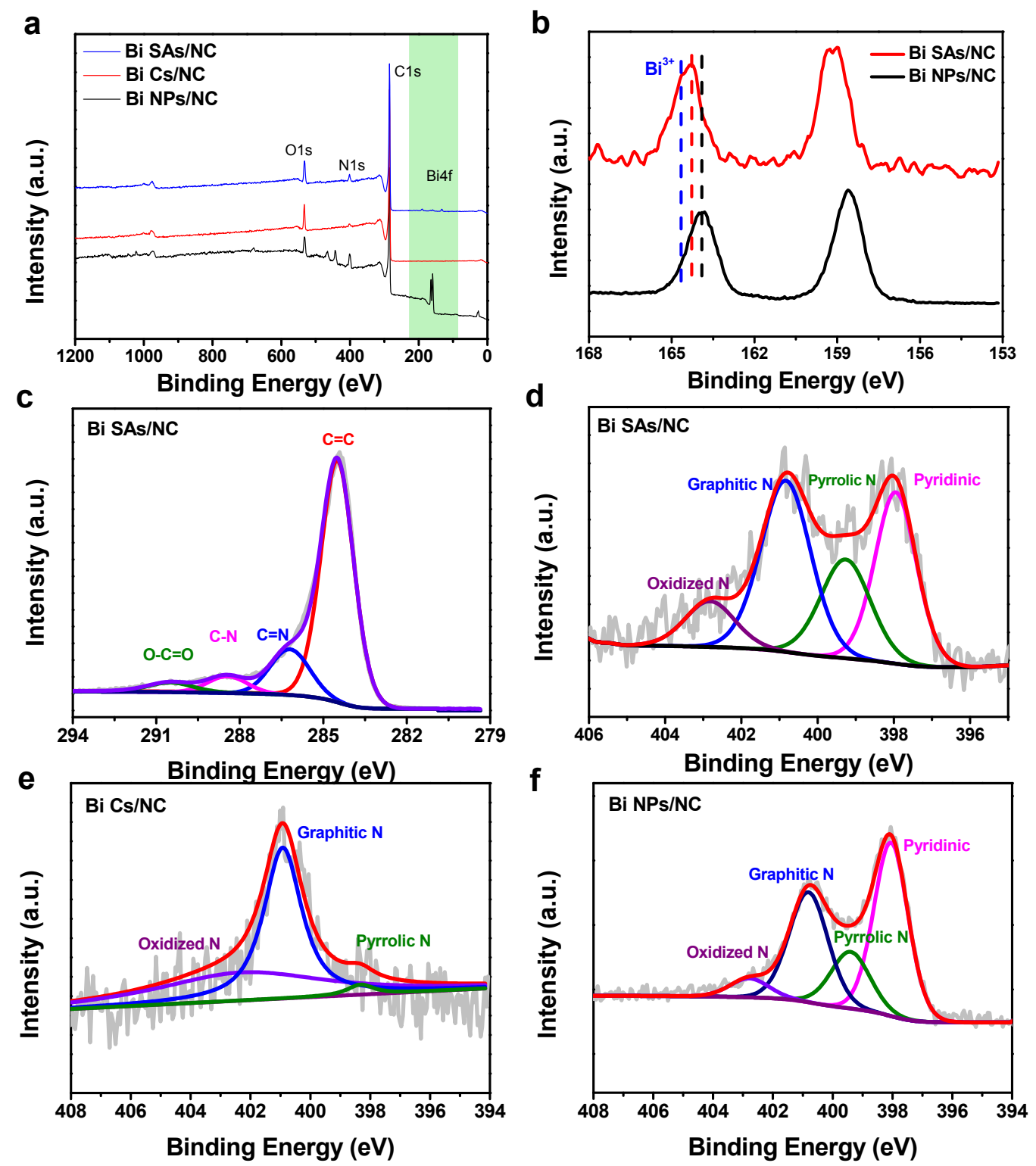

Figure S15. (a) XPS survey of Bi SAs/NC, Bi Cs/NC, and Bi NPs/NC. (b) XPS spectra for the $\mathrm{Bi} 4 \mathrm{f}$ regions of $\mathrm{Bi}$ SAs/NC and Bi NPs/NC. (c) C 1s spectra of Bi SAs/NC. (d-f) N 1s spectra of $\mathrm{Bi} \mathrm{SAs} / \mathrm{NC}, \mathrm{Bi} \mathrm{Cs} / \mathrm{NC}$, and Bi NPs/NC. As shown in the Figure S15d, the binding states of nitrogen in Bi SAs/NC can be fitted into four characteristic peaks: pyridinic $\mathrm{N}$ (397.86 eV), pyrrolic $\mathrm{N}(399.26 \mathrm{eV})$, graphitic $\mathrm{N}(400.86 \mathrm{eV})$, and oxidized $\mathrm{N}(402.86 \mathrm{eV})$. 


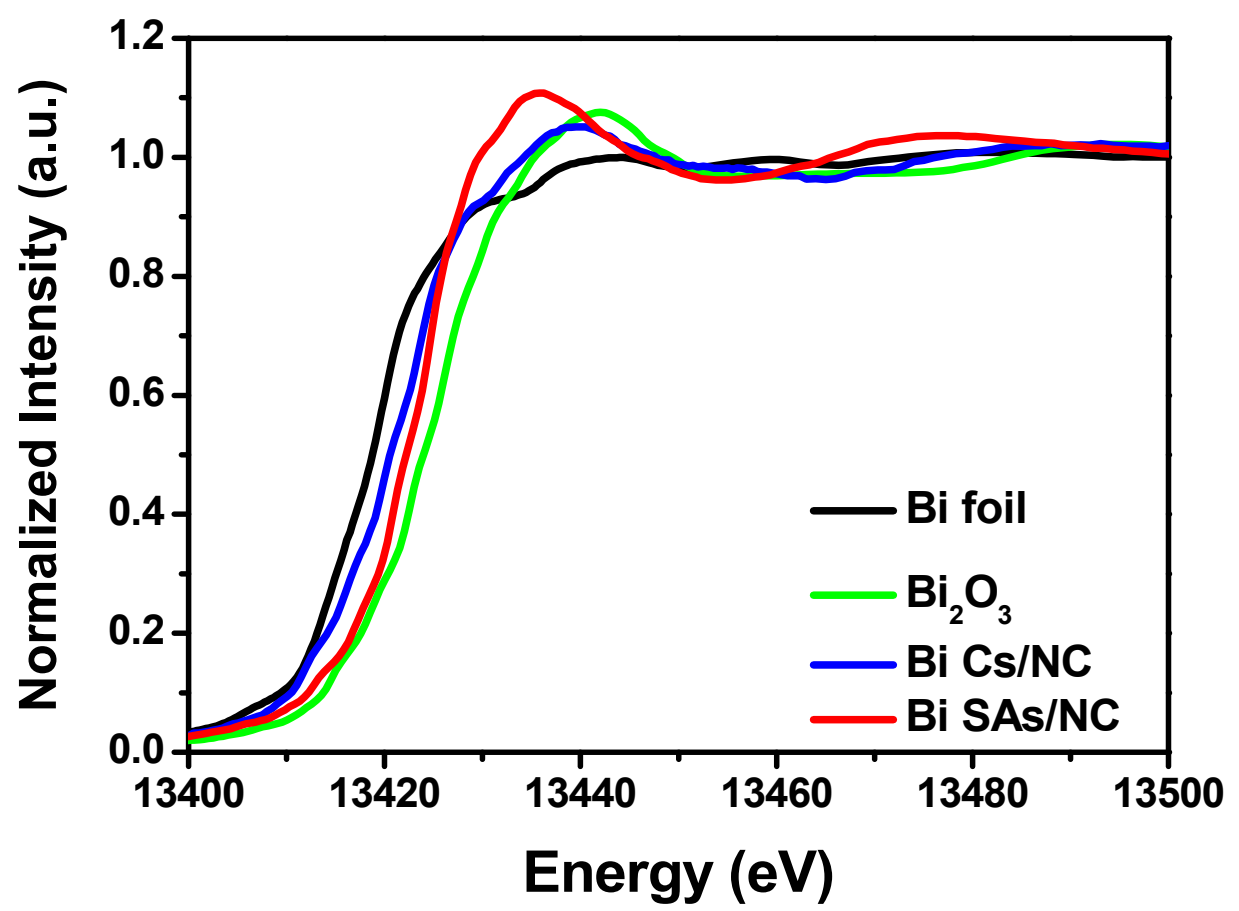

Figure S16. $\mathrm{Bi} \mathrm{L}_{3}$-edge XANES spectra of $\mathrm{Bi} \mathrm{SAs} / \mathrm{NC}, \mathrm{Bi} \mathrm{Cs} / \mathrm{NC} \mathrm{Bi}_{2} \mathrm{O}_{3}$, and $\mathrm{Bi}$ foil. 


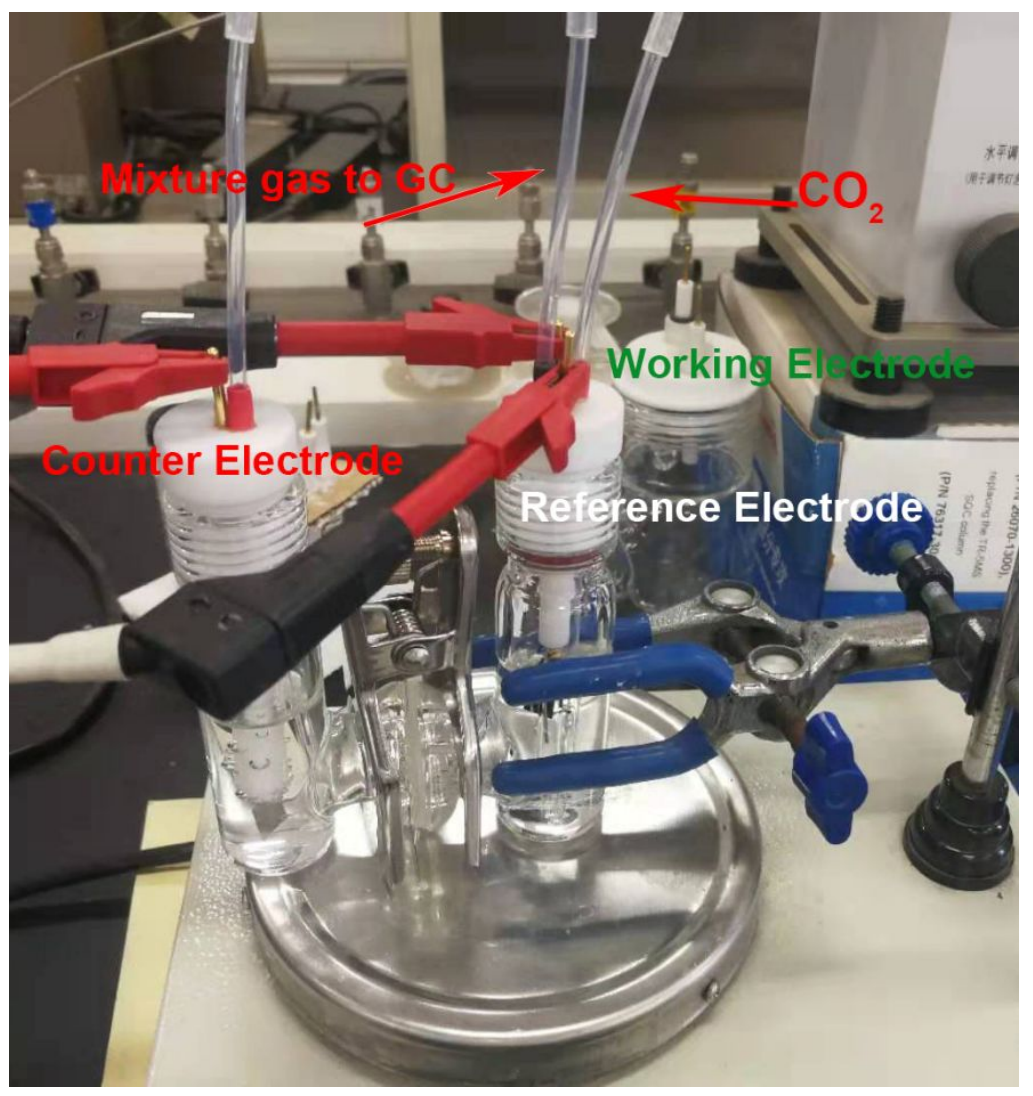

Figure S17. Digital photograph of an $\mathrm{H}$-type electrochemical cell for the $\mathrm{CO}_{2}$ reduction reaction. 

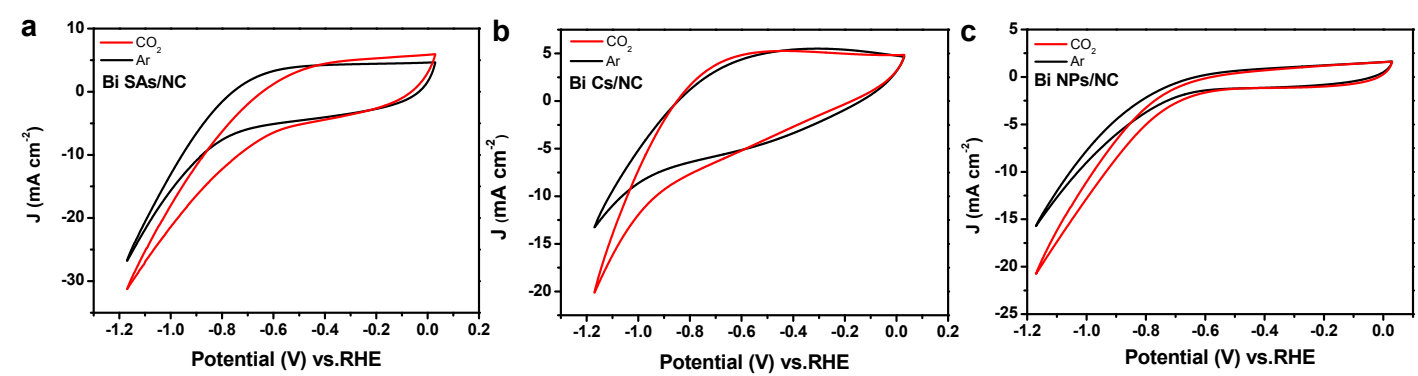

Figure S18. (a-c) The cyclic voltammetry curves for Bi SAs/NC, Bi Cs/NC, and Bi NPs/NC in Ar-saturated and $\mathrm{CO}_{2}$-saturated $0.1 \mathrm{M} \mathrm{NaHCO}_{3}$ (scan rate: $50 \mathrm{mV} \mathrm{s}^{-1}$ ).

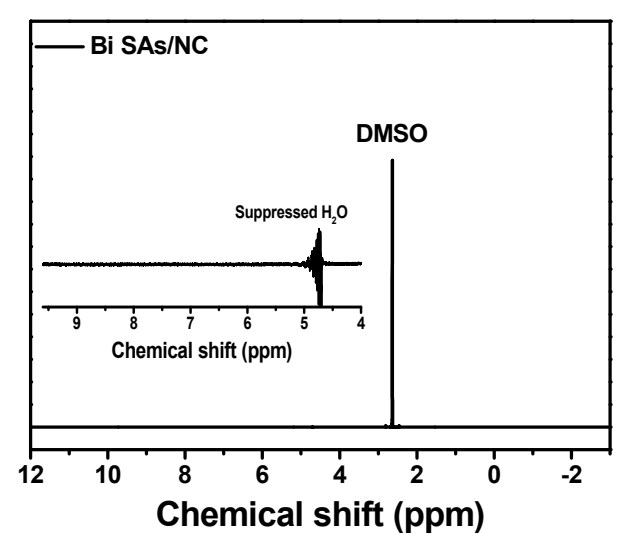

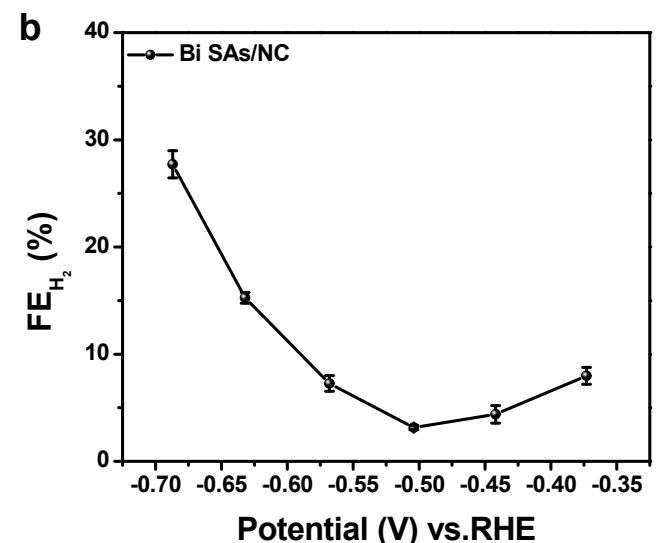

Figure S19. (a) Characterization for the liquid product of $\mathrm{Bi} S A s / N C$ after $1 \mathrm{~h} \mathrm{CO}_{2}$ reduction process at $-0.5 \mathrm{~V}$ vs RHE by nuclear magnetic resonance spectroscopy. (b) Faradaic efficiency for $\mathrm{H}_{2}$ production. Liquid products were analysed afterwards by quantitative NMR using dimethyl sulphoxide (DMSO) as an internal standard.

a

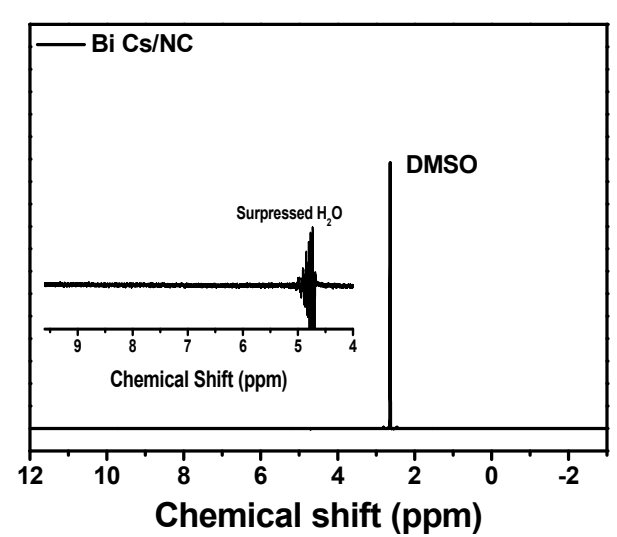

b

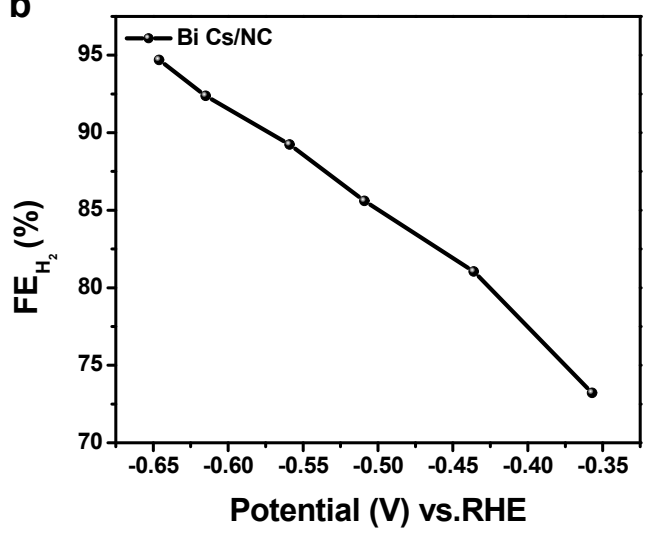


Figure S20. (a) Characterization for the liquid product of $\mathrm{Bi} \mathrm{Cs} / \mathrm{NC}$ after $1 \mathrm{~h} \mathrm{CO}_{2}$ reduction process at $-0.5 \mathrm{~V}$ by nuclear magnetic resonance spectroscopy. (b) Faradaic efficiency for $\mathrm{H}_{2}$ production.
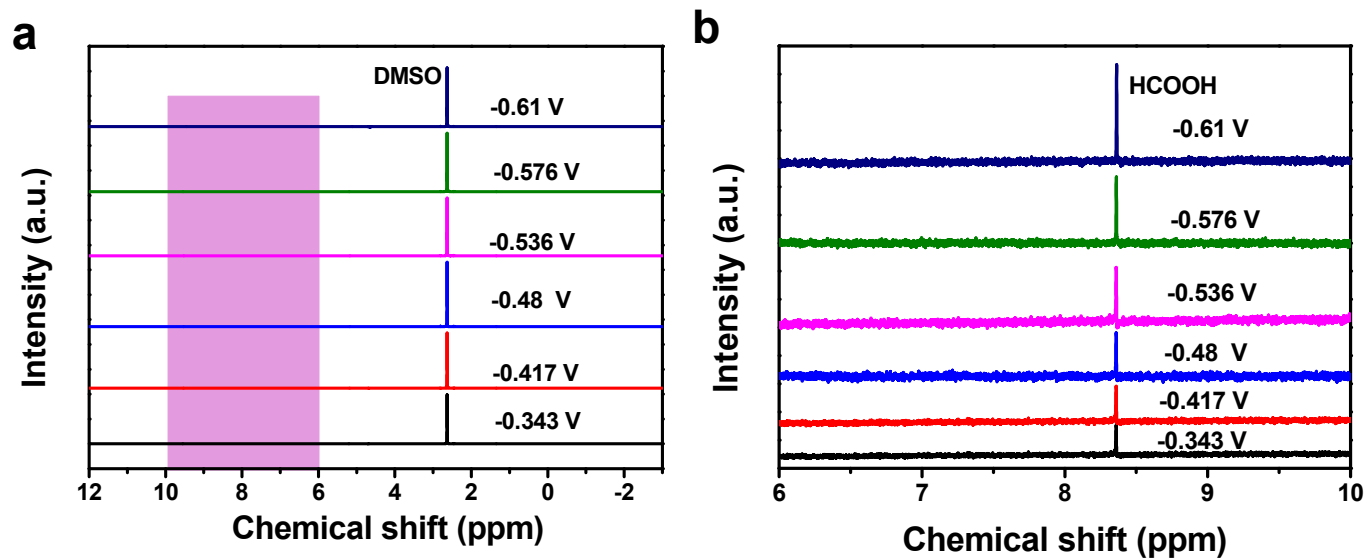

Figure S21. $(a, b)$ Characterization for the liquid product of $B i \mathrm{NPs} / \mathrm{NC}$ after $1 \mathrm{~h} \mathrm{CO}_{2}$ reduction process at different applied potentials by nuclear magnetic resonance spectroscopy. ${ }^{*}$ The chemical shift of $\mathrm{H}$ in $\mathrm{HCOO}$ - was around $8.36 \mathrm{ppm}$.

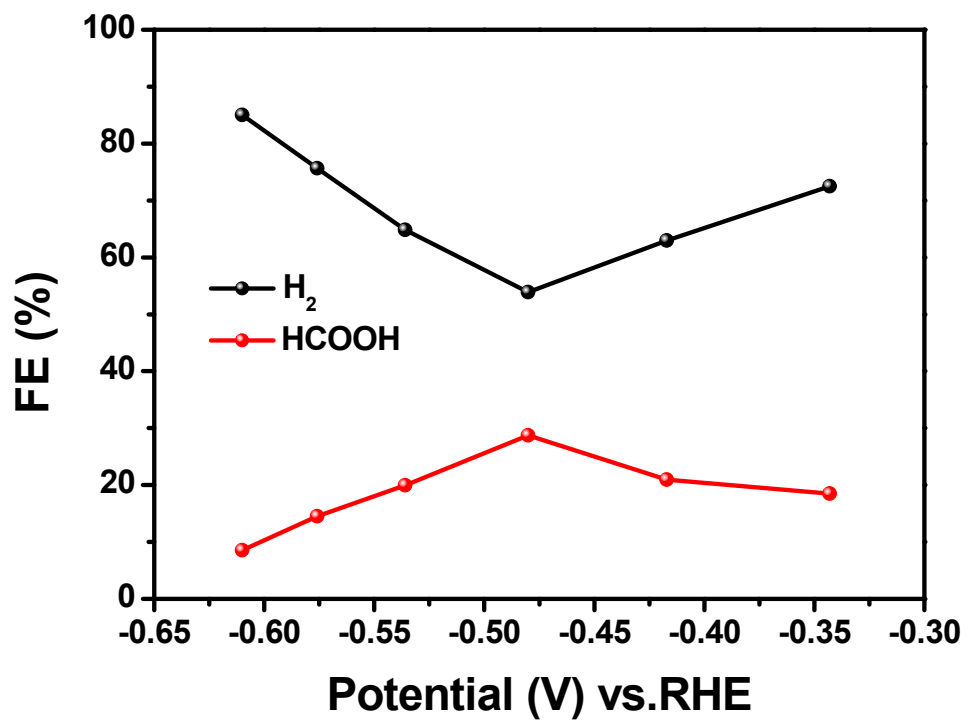

Figure S22. (a) Faradaic efficiency of Bi NPs/NC for $\mathrm{HCOOH}$ and $\mathrm{H}_{2}$ production. 


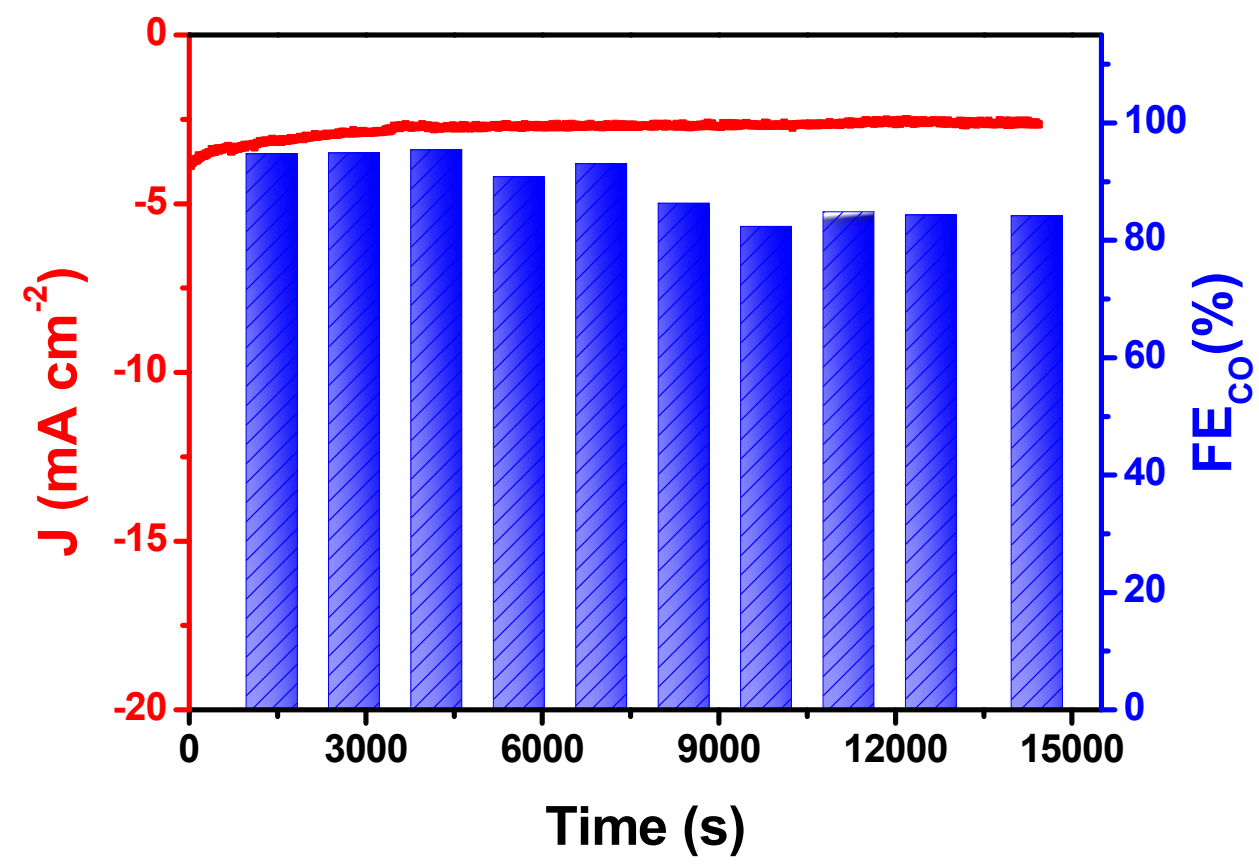

Figure S23. Stability of $\mathrm{Bi}$ SAs/NC at a potential of $-0.5 \mathrm{~V}$ vs RHE during $4 \mathrm{~h}$ (inset is $\mathrm{FE}_{\mathrm{CO}}$ at different time). Although the $\mathrm{FE}_{\mathrm{CO}}$ showed a fluctuate from $95 \%$ to the final $84.2 \%$, it was still relatively durable electrocatalysts toward $\mathrm{CO}_{2}$ reduction with a high selectivity.
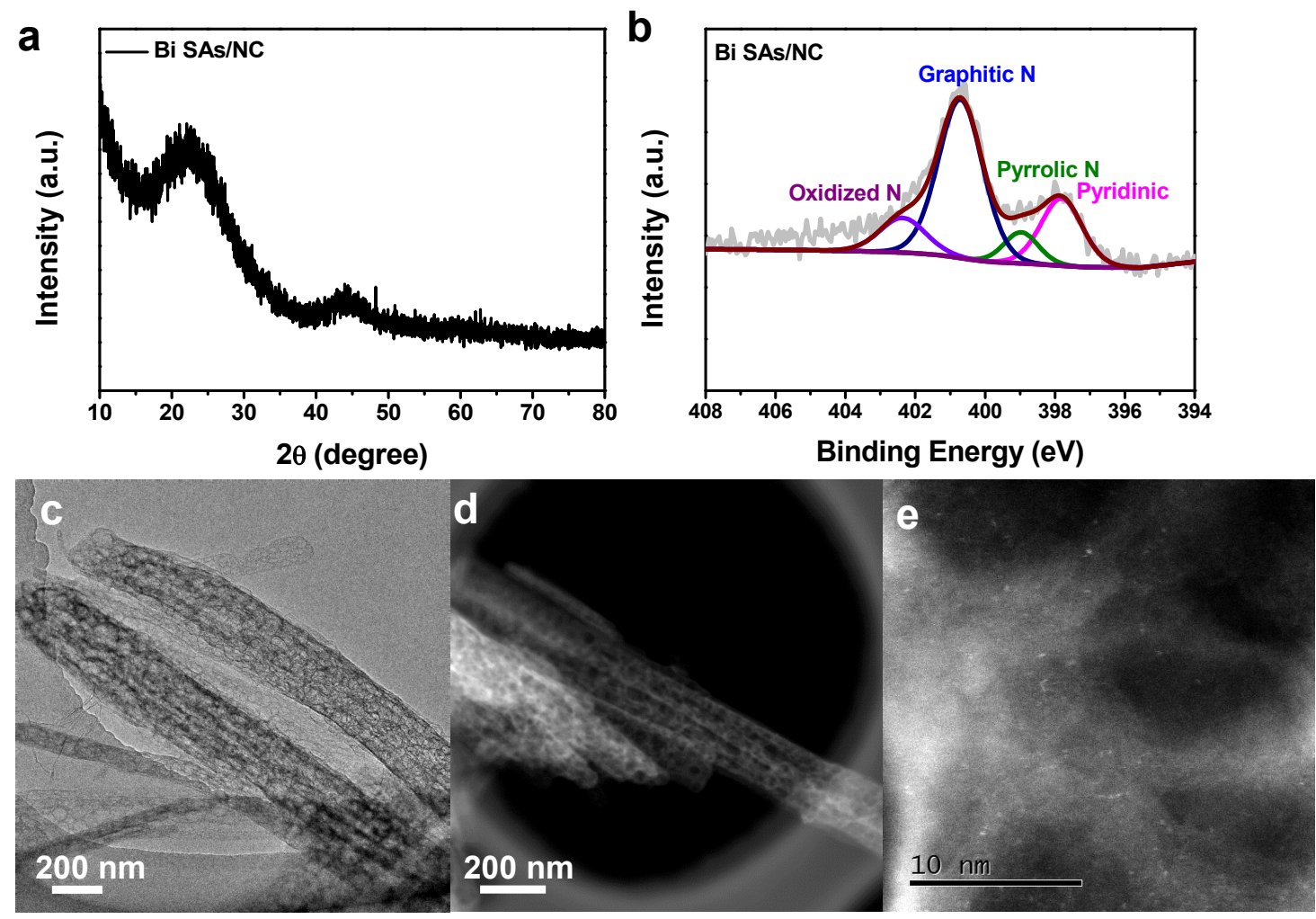

Figure S24. (a) XRD pattern, (b) XPS spectrum, (c) TEM, and (d-e) HAADF-STEM images of $\mathrm{Bi}$ SAs/NC after $4 \mathrm{~h}$ electrolysis. 

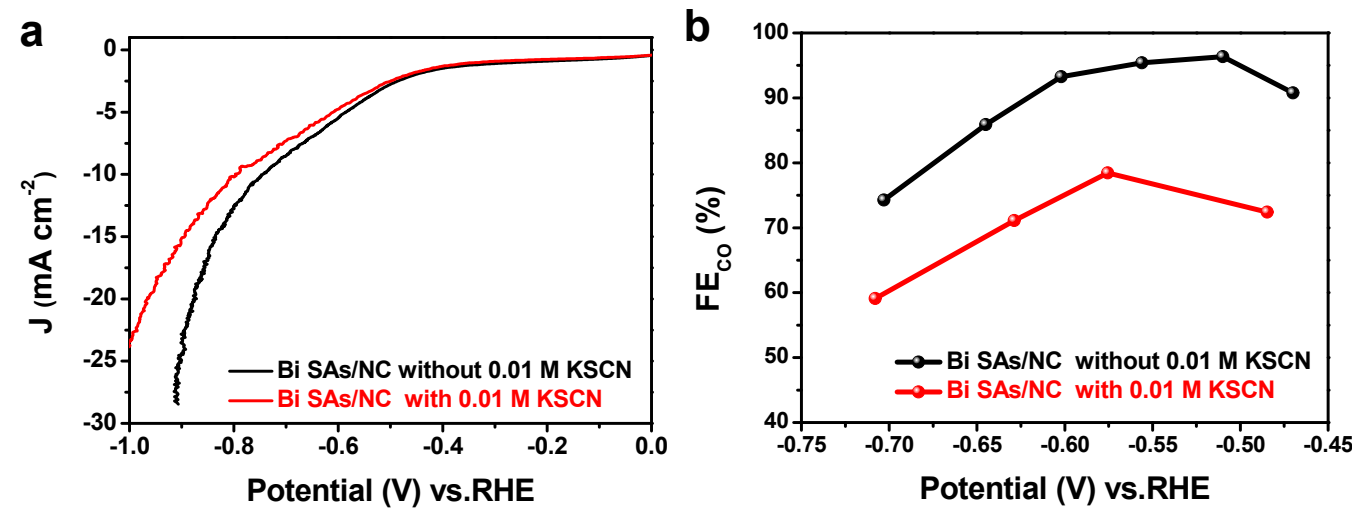

Figure S25. The $\mathrm{CO}_{2} \mathrm{RR}$ activity for $\mathrm{CO}$ formation on $\mathrm{Bi} A \mathrm{~S} / \mathrm{NC}$ before and after poisoning by $\mathrm{KSCN}$ in $\mathrm{CO}_{2}$-saturated $0.1 \mathrm{M} \mathrm{NaHCO}_{3}$. (a) LSV curves and (b) $\mathrm{FE}_{\mathrm{CO}}$ of Bi SAs/NC with $0.01 \mathrm{M}$ $\mathrm{KSCN}$ and without $0.01 \mathrm{M} \mathrm{KSCN}$.
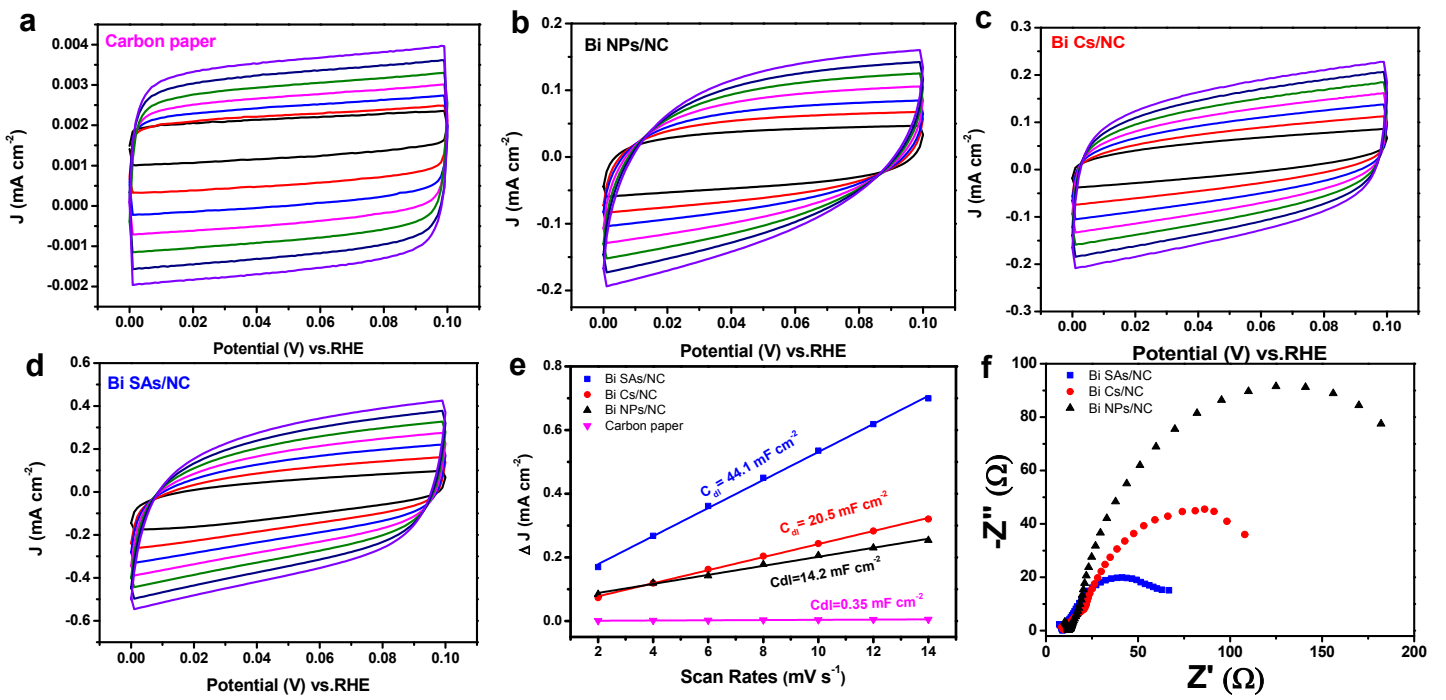

Figure S26. (a-e) The electrochemical capacitance measurements of carbon paper, Bi $\mathrm{NPs} / \mathrm{NC}, \mathrm{Bi} \mathrm{Cs} / \mathrm{NC}$, and Bi SAs/NC. (f) Electrochemical impedance spectroscopy (EIS) of catalysts in the frequency range of 0.01 to $100000 \mathrm{~Hz}$. Electrochemical capacitance measurements for the estimation of the electrochemical active surface area of catalysts. These catalysts were tested with scan rates ranging from 2 to $14 \mathrm{mV} \mathrm{s}^{-1}$ with an interval of 2 $\mathrm{mV} \mathrm{s}^{-1}$ at the potential window of $0 \mathrm{~V}$ to $0.1 \mathrm{~V}$ vs. RHE. The extraction of the double-layer capacitances of the samples, the electrochemical double-layer capacitance (Cdl), was estimated by plotting $\mathrm{Ja}-\mathrm{Jc}$ at $0.05 \mathrm{~V}$ vs. RHE against the scan rate, where the slope was twice that of Cdl. As shown in Figure S26e, the electrochemical double-layer capacitance (Cdl) of $\mathrm{Bi} \mathrm{SAs} / \mathrm{NC}(44.1 \mathrm{mF} \mathrm{cm}-2)$ was higher than both that of $\mathrm{Bi} \mathrm{Cs} / \mathrm{NC}\left(20.5 \mathrm{mF} \mathrm{cm}^{-2}\right)$ and $\mathrm{Bi}$ $\mathrm{NPs} / \mathrm{NC}\left(14.2 \mathrm{mF} \mathrm{cm}^{-2}\right)$, suggesting $\mathrm{Bi} \mathrm{SAs} / \mathrm{NC}$ possessed a significant larger electrochemically active surface area (ESCA). The semicircular characteristic of EIS curves (Figure 26f) indicated that the Bi SAs/NC had a smaller charge transfer resistance than other 
reference catalysts, demonstrating a fastest charge transfer rate for $\mathrm{Bi} \mathrm{SAs} / \mathrm{NC}$ in the $\mathrm{CO}_{2}$ reduction process.

a
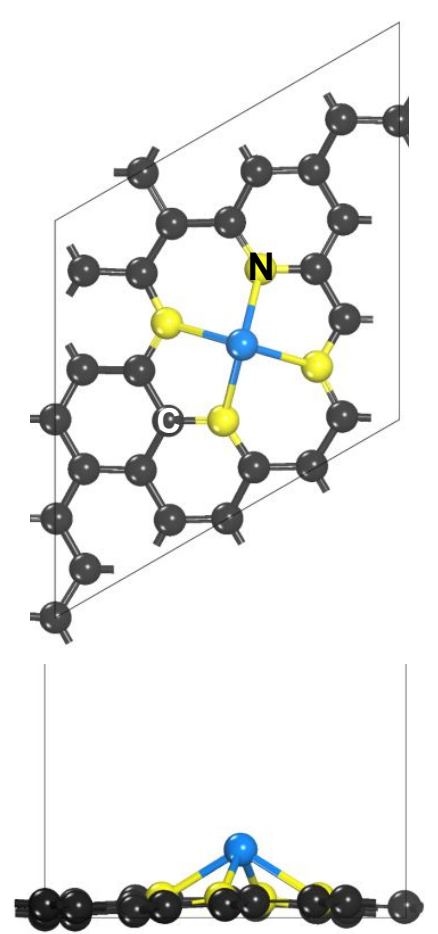

b
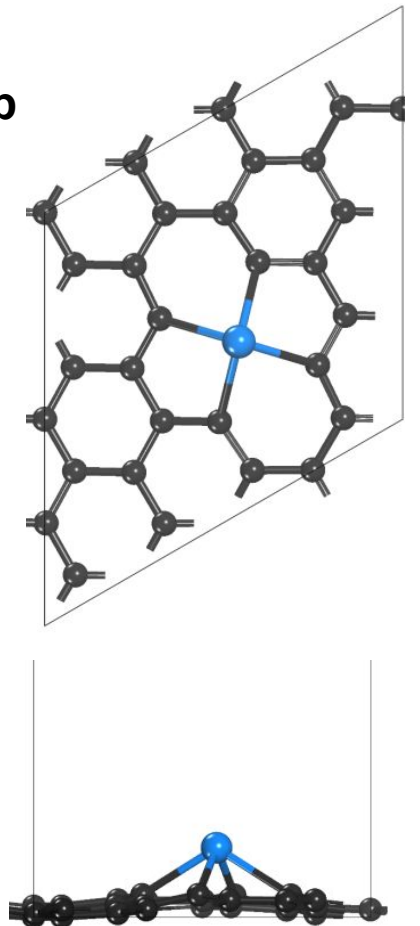

C
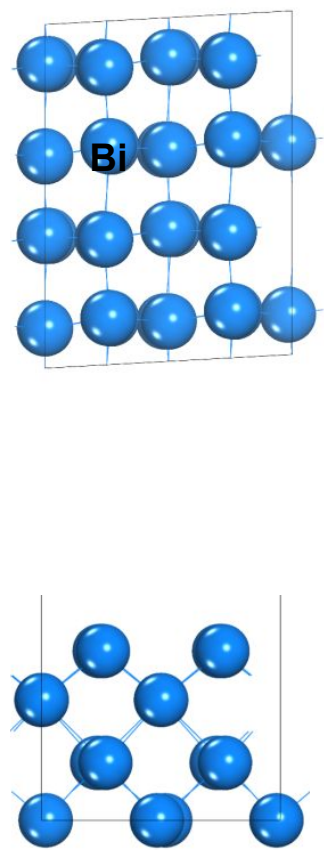

Figure S27: Schematic top and side views of (a) $\mathrm{BiN}_{4} / \mathrm{C}$, (b) $\mathrm{BiC}_{4}$, and (c) $\mathrm{Bi}(110)$ surfaces.



Figure S28. Adsorption configurations of $\mathrm{CO}_{2}, \mathrm{COOH}, \mathrm{CO}, \mathrm{H}$ and $\mathrm{HCOO}$ on $\mathrm{BiN}_{4} / \mathrm{C}$ surface. 


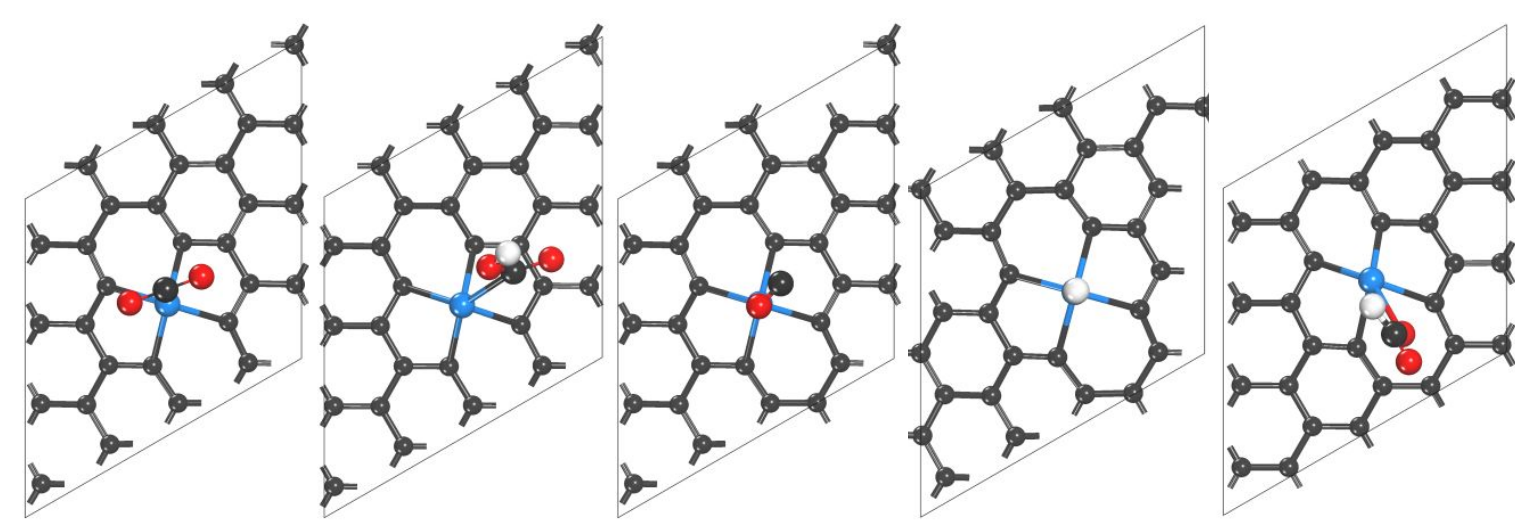

Figure S29. Adsorption configurations of $\mathrm{CO}_{2}, \mathrm{COOH}, \mathrm{CO}, \mathrm{H}$ and $\mathrm{HCOO}$ on $\mathrm{BiC}_{4}$ surface.

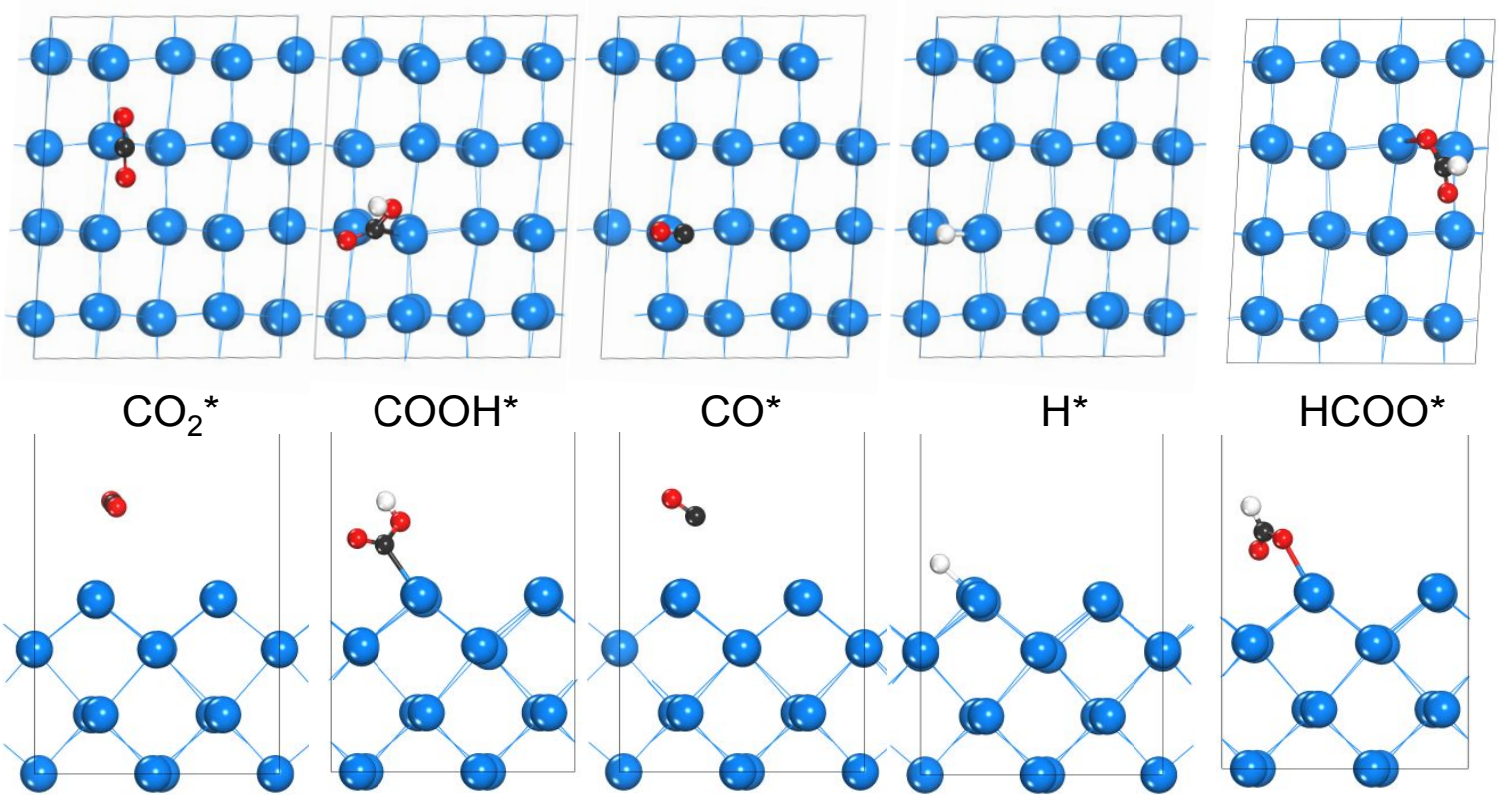

Figure 30. Adsorption configurations of $\mathrm{CO}_{2}, \mathrm{COOH}, \mathrm{CO}, \mathrm{H}$ and $\mathrm{HCOO}$ on $\mathrm{Bi}(110)$ surface. 


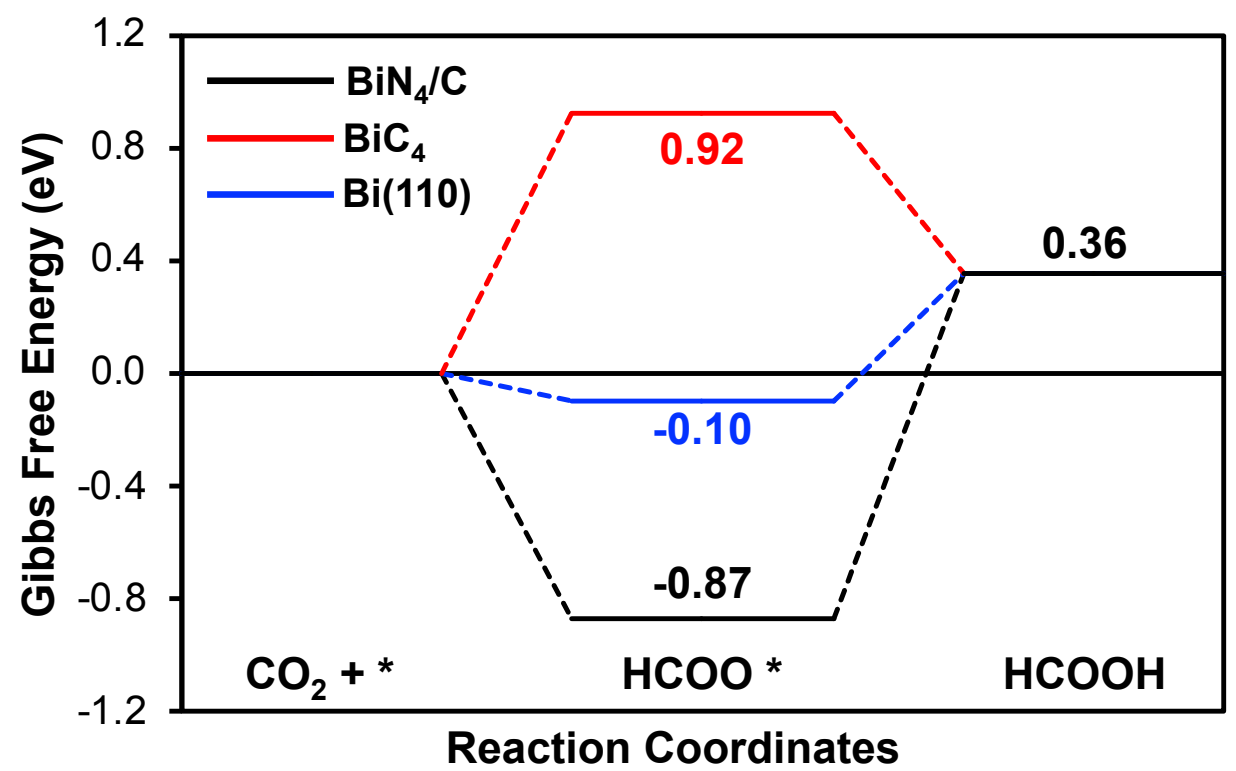

Figure S31. The Gibbs free energy diagram for the formate reaction pathways on $\mathrm{BiN}_{4} / \mathrm{C}$, $\mathrm{Bi}(110)$ and $\mathrm{BiC}_{4}$ surfaces. The theoretical overpotential for formate pathway $(1.23 \mathrm{~V})$ was higher than $\mathrm{CO}$ pathway $(0.58 \mathrm{~V})$ on $\mathrm{BiN}_{4} / \mathrm{C}$ catalyst, indicating its good performance for $\mathrm{CO}$ production. The $\mathrm{Bi}(110)$ and $\mathrm{BiC}_{4}$ catalysts had higher theoretical overpotential for $\mathrm{CO}$ pathway than formate pathway, indicating their less promising performances in CO production. 
Table S1. The surface area and pore size distribution of different samples.

\begin{tabular}{ccc}
\hline Sample & Surface area $\left(\mathbf{m}^{\mathbf{2}} \mathbf{g}^{-1}\right)$ & Pore Size $(\mathbf{n m})$ \\
\hline Bi-MOF & 240.2 & $1.75 \mathrm{~nm}$ \\
Bi SAs/NC & 355.4 & $2.2,3.6$ \\
Bi Cs/NC & 310.9 & 2.9 \\
Bi NPs/NC & 66.4 & 1.85 \\
\hline
\end{tabular}

Table S2. Structural parameters extracted from the Bi K-edge EXAFS fitting. $\left(\mathrm{S}_{0}{ }^{2}=0.85\right)$

\begin{tabular}{lcccccc}
\hline Sample & $\begin{array}{l}\text { Scattering } \\
\text { pair }\end{array}$ & CN & $\mathbf{R}(\AA)$ & $\sigma^{2}\left(10^{-3} \AA^{2}\right)$ & $\Delta \mathrm{E}_{0}(\mathrm{eV})$ & $\mathbf{R}$ factor \\
\hline $\mathrm{Bi} \mathrm{SAs} / \mathrm{NC}$ & $\mathrm{Bi}-\mathrm{N}$ & 3.8 & 1.98 & 5.2 & 1.5 & 0.005 \\
\hline
\end{tabular}

$\mathrm{S}_{0}{ }^{2}$ is the amplitude reduction factor; $\mathrm{CN}$ is the coordination number; $\mathrm{R}$ is interatomic distance (the bond length between central atoms and surrounding coordination atoms); $\sigma^{2}$ is Debye-Waller factor (a measure of thermal and static disorder in absorber-scatterer distances); $\Delta \mathrm{E}_{0}$ is edge-energy shift (the difference between the zero kinetic energy value of the sample and that of the theoretical model). $R$ factor is used to value the goodness of the fitting.

Error bounds that characterize the structural parameters obtained by EXAFS spectroscopy were estimated as $N \pm 20 \% ; R \pm 1 \% ; \sigma^{2} \pm 20 \% ; \Delta E_{0} \pm 20 \%$. Bi SAs/NC (FT range: $2.0-11.0 \AA^{-1}$; fitting range: $0.8-2.2 \AA$ ) 
Table S3. Comparison of the $\mathrm{CO}_{2}$ performance for $\mathrm{Bi} \mathrm{SAs} / \mathrm{NC}$ with some representative $\mathrm{CO}_{2}$ to $\mathrm{CO}$ reduction catalysts recently reported.

\begin{tabular}{|c|c|c|c|c|c|}
\hline Catalyst & $\mathrm{FE}_{\mathrm{co}}(\%)$ & $\begin{array}{l}\text { Current density } \\
\qquad(\mathrm{mA} \mathrm{cm}-2)\end{array}$ & $\begin{array}{l}\text { Overpotential } \\
(\mathrm{eV})\end{array}$ & TOF & Ref. \\
\hline Bi SAs/NC & 97 & 4 & 390 & 5535 & $\begin{array}{l}\text { This } \\
\text { work }\end{array}$ \\
\hline Au nanowires & 94 & 8.16 & 350 & 72 & 12 \\
\hline COF-367-Co & 91 & 3.3 & 670 & 165 & 13 \\
\hline Co-MOF & 76 & 1 & $\sim 600$ & 200 & 14 \\
\hline $\mathrm{CuO} / \mathrm{SnO}_{2}$ & 90 & 2 & 490 & 886 & 15 \\
\hline $\begin{array}{c}\text { Co-protoporph } \\
\text { yrin }\end{array}$ & 40 & -0.16 & 590 & 2880 & 16 \\
\hline $\mathrm{Ni}$ SAs/N-C & 70.3 & 10.48 & 890 & 5273 & 17 \\
\hline Co-N ${ }_{5} / \mathrm{HNPCS}$ & 99.3 & 10.2 & 680 & 480.2 & 18 \\
\hline $\mathrm{s}$ & $\sim 94$ & $\sim 2.5$ & 490 & $\mathrm{~N} / \mathrm{A}$ & \\
\hline $\mathrm{Cu} / \mathrm{SnO}_{2}$ & 93 & 4.6 & 590 & $\mathrm{~N} / \mathrm{A}$ & 19 \\
\hline Tri-Ag-NPs & 96.8 & $\sim 2$ & 746 & $\mathrm{~N} / \mathrm{A}$ & 20 \\
\hline FePGH & 96 & 0.42 & 390 & 9360 & 21 \\
\hline CoPP@CNT & 98 & 3.65 & 490 & 7560 & 22 \\
\hline Cu-APC & 92 & 9.34 & 670 & N/A & 23 \\
\hline
\end{tabular}


Movie S1. A movie of TEM images showing Bi-MOF transforming to Bi SAs/NC taken in the temperature window from 23 to $600^{\circ} \mathrm{C}$ under $\mathrm{Ar}$ atmosphere. 


\section{Reference}

(1) Kresse, G.; Furthmüller, Efficiency of ab-initio total energy calculations for metals and semiconductors using a plane-wave basis set.J. Comput. Mater. Sci. 1996, 6, 15-50.

(2) Kresse, G.; Furthmüller, Efficient iterative schemes for ab initio total-energy calculations using a plane-wave basis set. J. Phys. Rev. B 1996, 54, 11169-11186.

(3) Blochl, P. E. Projector augmented-wave method. Phys. Rev. B 1994, 50, 17953-17979.

(4) Kresse, G. From Ultrasoft Pseudopotentials to the Projector Augmented-Wave Method. Phys. Rev. B 1999, 59, 1758-1775.

(5) Perdew, J. P.; Burke, K.; Ernzerhof, M. Generalized gradient approximation made simple. Phys. Rev. Lett. 1996, 77, 3865-3868.

(6) Grimme, S.; Antony, J.; Ehrlich, S.; Krieg, S. A consistent and accurate ab initio parametrization of density functional dispersion correction (DFT-D) for the 94 elements $\mathrm{H}-\mathrm{Pu}$. J. Chem. Phys. 2010, 132, 154104.

(7) Nørskov, J. K.; Rossmeisl, J.; Logadottir, A.; Lindqvist, L.; Kitchin, J. R.; Bligaard, T.; Jonsson, H. Origin of the overpotential for oxygen reduction at a fuel-cell cathode. J. Phys. Chem. B 2004, 108, 17886-17892.

(8) Peterson, A. A.; Abild-Pedersen, F.; Studt, F.; Rossmeisl, J.; Nørskov, J. K. How copper catalyzes the electroreduction of carbon dioxide into hydrocarbon fuels. Energy Environ. Sci. 2010, 3, 1311-1315.

(9) Kim, D.; Xie, C.; Becknell, N.; Yu, Y.; Karamad, M.; Chan, K.; Crumlin, E. J.;Norskov, J. K.; Yang, P. Electrochemical Activation of $\mathrm{CO}_{2}$ through Atomic Ordering Transformations of $\mathrm{AuCu}$ Nanoparticles. J. Am. Chem. Soc. 2017, 139, 8329-8336.

(10) Liu, Y.; Wang, G.; Dong, J.; An, Y.; Huang, B.; Qin, X.; Zhang, X.; Dai, Y. A bismuth based layer structured organic-inorganic hybrid material with enhanced photocatalytic activity $J$. Colloid Interface Sci. 2016, 469, 231-236.

(11) Jeon, H. R.; Lee, D. W.; Ok, K. M. Bi $\left[\mathrm{NC}_{5} \mathrm{H}_{3}\left(\mathrm{CO}_{2}\right)_{2}\right]\left(\mathrm{OH}_{2}\right) x F(x=1$ and 2): new one-dimensional $\mathrm{Bi}$-coordination materials-reversible hydration and topotactic decomposition to a- $\mathrm{Bi}_{2} \mathrm{O}_{3}$. J. Solid State Chem. 2012, 187, 83-88.

(12) Zhu W.; Zhang Y. J.; Zhang H.; Lv H.; Li Q.; Michalsky R.; Peterson A. A.; Sun S. Active and Selective Conversion of $\mathrm{CO}_{2}$ to $\mathrm{CO}$ on Ultrathin Au Nanowires. J. Am. Chem. Soc. 2014, 136, 16132-16135. 
(13) Lin S.; Diercks C. S.; Zhang Y. B.; Kornienko N.; Nichols E. M.; Zhao Y.; Paris A. R.; Kim D.; Yang P.; Yaghi O. M.; Chang C. J. Electrocatalytic reduction of carbon dioxide to carbon monoxide and methane at an immobilized cobalt protoporphyrin. Science 2015, 349, 1208-1213.

(14) Kornienko, N.; Zhao, Y.; Kley, C. S.; Zhu, C.; Kim, D.; Lin, S.;Chang, C. J.; Yaghi, O. M.; Yang, P. Metal-Organic Frameworks for Electrocatalytic Reduction of Carbon Dioxide. J. Am. Chem. Soc. 2015, 137, 14129-14135.

(15) Schreier, M.; Heroguel, F.; Steier, L.; Ahmad, S.; Luterbacher, J. S.; Mayer, M. T.; Luo, J.; Gratzel, M. Solar conversion of $\mathrm{CO}_{2}$ to $\mathrm{CO}$ using Earth-abundant electrocatalysts prepared by atomic layer modification of CuO. Nat. Energy 2017, 2, 17087.

(16) Shen, J.; Kortlever, R.; Kas, R.; Birdja, Y. Y.; DiazMorales, O.; Kwon, Y.; Ledezma-Yanez, I.; Schouten, K. J. P.; Mul, G.; Koper, M. T. M. Electrocatalytic reduction of carbon dioxide to carbon monoxide and methane at an immobilized cobalt protoporphyrin. Nat. Commun. 2015, 6,8177 .

(17) Zhao, C.; Dai, X.; Yao, T.; Chen, W.; Wang, X.; Wang, J.; Yang, J.; Wei, S.; Wu, Y.; Li, Y. Ionic Exchange of Metal-Organic Frameworks to Access Single Nickel Sites for Efficient Electroreduction of $\mathrm{CO}_{2}$. J. Am. Chem. Soc. 2017, 139, 8078-8081.

(18) Pan, Y.; Lin, R.; Chen, Y.; Liu, S.; Zhu, W.; Cao, X.; Chen, W.; Wu, K.; Cheong, W. C.; Wang, Y.; Zheng, L.; Luo, J.; Lin, Y.; Liu, Y.; Liu, C.; Li, J.; Lu, Q.; Chen, X.; Wang, D.; Peng, Q.; Chen, C.; Li, Y. Design of Single-Atom Co- $\mathrm{N}_{5}$ Catalytic Site: A Robust Electrocatalyst for $\mathrm{CO}_{2}$ Reduction with Nearly $100 \%$ CO Selectivity and Remarkable Stability. J. Am. Chem. Soc. 2018, 140, 4218-4221.

(19) Li, Q.; Fu, J.; Zhu, W.; Chen, Z.; Shen, B.; Wu, L.; Xi, Z.; Wang, T.; Lu, G.; Zhu, J.-j.; Sun, $\mathrm{S}$. Tuning Sn-Catalysis for Electrochemical Reduction of $\mathrm{CO}_{2}$ to $\mathrm{CO}$ via the Core/Shell $\mathrm{Cu} / \mathrm{SnO}_{2}$ Structure. J. Am. Chem. Soc. 2017, 139, 4290-4293.

(20) Liu, S.; Tao, H.; Zeng, L.; Liu, Q.; Xu, Z.; Liu, Q.; Luo, J. Shape-Dependent Electrocatalytic Reduction of $\mathrm{CO}_{2}$ to $\mathrm{CO}$ on Triangular Silver Nanoplates. J. Am. Chem. Soc. 2017, 139, 2160-2163.

(21) Choi, J.; Kim, J.; Wagner, P.; Gambir, S.; Jalili, A. R.; Byun, S.; Sayyar, S.; Lee, Y. M.; MacFarlane, D.; Wallace, G. G. Energy efficient electrochemical reduction of $\mathrm{CO}_{2}$ to $\mathrm{CO}$ using a three-dimensional porphyrin/graphene hydrogel. Energy Environ. Sci. 2019, 12, 747-755.

(22) Zhu, M.; Chen, J.; Huang, L.; Ye, R.; Xu, J.; Han, Y. F. Covalently Grafting Cobalt Porphyrin onto Carbon Nanotubes for Efficient $\mathrm{CO}_{2}$ Electroreduction. Angew. Chem. Int. Ed. 2019, 58, 6595-6599.

(23) Jiao, J.; Lin, R.; Liu, S.; Cheong, W. C.; Zhang, C.; Chen, Z.; Pan, Y.; Tang, J.; Wu, K.; Hung, S. F. Chen, H. M.; Zheng, L.; Lu, Q.; Yang, X.; Xu, B.; Xiao, H.; Li, J.; Wang, D.; Peng, Q.; Chen, C.; Li, Y. Copper atom-pair catalyst anchored on alloy nanowires for selective and efficient electrochemical reduction of $\mathrm{CO}_{2}$. Nat. Chem. 2019, 11, 222-228. 